\title{
Novel strong promoter of antimicrobial peptides gene pro-SmAMP2 from chickweed (Stellaria media)
}

\author{
Roman A. Komakhin ${ }^{1 *}$, Denis A. Vysotskii ${ }^{1}$, Rahim R. Shukurov², Vera D. Voblikova', Vera V. Komakhina', \\ Svetlana R. Strelnikova ${ }^{1}$, Ekaterina M. Vetchinkina ${ }^{1}$ and Alexey V. Babakov ${ }^{1}$
}

\begin{abstract}
Background: In a previous study we found that in chickweed the expression level of the pro-SmAMP2 gene was comparable or even higher to that of the $\beta$-actin gene. This high level of the gene expression has attracted our attention as an opportunity for the identification of novel strong promoters of plant origin, which could find its application in plant biotechnology. Therefore, in the present study we focused on the nucleotide sequence identification and the functional characteristics of the pro-SMAMP2 promoter in transgenic plants.
\end{abstract}

Results: In chickweed (Stellaria media), a 2120 bp promoter region of the pro-SMAMP2 gene encoding antifungal peptides was sequenced. Six 5'-deletion variants $-2120,-1504,-1149,-822,-455$, and -290 bp of pro-SmAMP2 gene promoter were fused with the coding region of the reporter gene gusA in the plant expression vector pCambia1381Z. Independent transgenic plants of tobacco Nicotiana tabacum were obtained with each genetic structure. GUS protein activity assay in extracts from transgenic plants showed that all deletion variants of the promoter, except -290 bp, expressed the gusA gene. In most transgenic plants, the GUS activity level was comparable or higher than in plants with the viral promoter CaMV 35S. GUS activity remains high in progenies and its level correlates positively with the amount of gusA gene mRNA in $T_{3}$ homozygous plants. The activity of the pro-SmAMP2 promoter was detected in all organs of the transgenic plants studied, during meiosis and in pollen as well.

Conclusion: Our results show that the pro-SMAMP2 promoter can be used for target genes expression control in transgenic plants.

Keywords: Stellaria media, Nicotiana tabacum, pro-SmAMP2, Promoter, Expression control, Transgenic plants

\section{Background}

Currently, promoters of many genes from a wide range of organisms are used in genetic engineering of plants. Promoters are traditionally divided into three types: constitutive, tissue-specific, and inducible [1]. In former times, virtually all transgenic plants contained two heterologous genes: one, a selection marker gene controlled by a constitutive promoter and the other a target gene controlled by a promoter of any type to change the plant phenotype. At present, multigene transformation allows the import of entire metabolic pathways into plants,

\footnotetext{
* Correspondence: recombination@iab.ac.ru

${ }^{1}$ All-Russia Research Institute of Agricultural Biotechnology, Timiriazevskaya

42, 127550 Moscow, Russia

Full list of author information is available at the end of the article
}

including expression of protein complexes consisting of several target genes for the generation of transgenic plants producing multiple compounds simultaneously $[2,3]$. Either a number of different promoters with similar level and profile of expression, or several copies of the same promoter must be used in one genetic construct for multigene transformation. Both approaches are complicated for a number of reasons. Firstly, there is a lack of available promoters with the necessary parameters. Secondly, the introduction of repetitive sequences in the same or different loci of a transgenic plant genome can have a negative effect on the expression and inheritance of heterologous genes due to the effect of homology-dependent gene silencing [4-6]. 
Up to now, the constitutive promoter CaMV 35S, created on the basis of shell protein $35 \mathrm{~S}$ gene promoter region from cauliflower mosaic virus CaMV, is most widely used in vectors for genetic transformation of plants $[1,7,8]$. The CaMV $35 S$ promoter usually provides a high expression level of heterologous genes in plants, but it has some significant drawbacks. The promoter originates from a virus and infection of transgenic plants with CaMV virus may lead to the silencing of a heterologous gene controlled by $C a M V 35 S$ [9]. In addition, the widespread use of the CaMV $35 S$ promoter increases the probability to inactivate expression of heterologous genes under its control as a result of the homologous recombination $[10,11]$.

In addition to CaMV 35S, a number of other viral promoters are used for plant biotechnology (see the review by Porto et al. [8]). Recently, a highly efficient promoter was created from individual parts of different viral promoters $[12,13]$. Such a widespread use of viral promoters is in part due to the lack of well-characterized strong plant gene promoters, particularly from dicotyledons.

For monocotyledonous plants, strong promoters are known, such as $A c t 1$ and $Z m U b i$, which are already used in crop plant genetic engineering for quite a long time [14-16]. Recently, several strong and constitutive promoters APX, PGD1 and R1G1B from rice (Oryza sativa) were proposed for biotechnology of the same plant, which performed significantly better than the previously studied promoters Act1 and ZmUbi [17]. Strong and constitutive promoters of ubiquitin genes $R U B 2$ from $O$. sativa and UBI10 from Brachypodium distachyon were characterized and demonstrated to exceed CaMV $35 S$ in activity up to 35 -fold in transgenic monocotyledonous plants $[18,19]$.

At the same time, a number of strong and constitutive promoters were cloned for genetic engineering of dicotyledonous plants, but they not perform as well as those from the monocots described above. The promoters of $U B Q 1$ and UBQ6 genes from Arabidopsis thaliana are active in all tissues of tobacco (Nicotiana tabacum) at the level of viral CaMV $35 S$ promoter [20]. Quantification of promoter strength using transient expression in lima bean (Phaseolus lunatus) cotyledonary tissue showed that Gmubi and GmScream promoters from soybean (Glycine max Merr.) yielded from 2 to 7 -fold higher expression than a standard CaMV $35 S$ promoter $[21,22]$. The promoter of the acetolactate synthase ALS3 gene from cabbage (Brassica oleracea) is constitutive and comparable in efficiency to CaMV $35 S$ [23]. Use of the strong constitutive promoter MtHP from Medicago truncatula to drive gus expression in Arabidopsis, showed around $50 \%$ higher GUS activity as compared to the $C a M V 35 S$ promoter. The activity of this promoter in transgenic plants of clover (Trifolium repens) and alfalfa (Medicago sativa) was 1.75 and 1.4 times higher than that of $C a M V 35 S$, respectively [24]. The promoter of ACC-synthase VR-ACS1 gene from mung bean (Vigna radiata L.) demonstrated greater efficiency producing up to 6 times higher activity of the reporter proteins in transgenic tobacco and Arabidopsis, compared to the CaMV $35 S$ [25]. The apparent superiority of the VR-ACS1 promoter over the viral one was not only the result of transcriptional activation but also of more efficient translation.

Despite the abundance of literature on the use of plant promoters in plant biotechnology, the lack of effective promoters for high expression of target genes still exists.

In this study we focused on another group of plant genes that can be a source of effective promoters. When studying antifungal peptides of chickweed (Stellaria media), we found that the expression of their genes proSmAMP1 and pro-SmAMP2 is high and that it increases when $S$. media is treated by the elicitor methyl jasmonate or infected by pathogenic fungi [26]. The proSmAMP1 gene expression increased from 10 to 70 times reaching the level of the chickweed house-keeping gene $\beta$-actin. The expression of the other gene, pro-SmAMP2, is rather constitutive because its activity does not change so much under the influence of the above factors (2-5 times). At the same time its normal level of activity was unusually high in different organs (stem, leaves, roots, flowers), comparable or superior to the level of $\beta$-actin expression.

The high expression level of pro-SmAMP2 gene indicates that this gene has a strong promoter, which may be of interest for application in plant biotechnology. For that reason, we identified the promoter sequence and studied the properties of the pro-SmAMP2 gene promoter.

\section{Results}

Cloning the nucleotide sequence of pro-SmAMP2 gene promoter region and production of genetic constructs for plant transformation

As a result of "genome walking", a $2400 \mathrm{bp}$ target fragment of $S$. media genome was amplified. Its sequencing showed that the fragment includes part of the coding sequence of the pro-SmAMP2 gene and $2160 \mathrm{bp} 5$ '-flanking region from the translation start site (ATG codon) including $40 \mathrm{bp}$ of pro-SmAMP2 gene 5 '-UTR. The nucleotide sequence including the expected promoter region was analyzed by programs PLACE $[27,28]$ and PlantCARE [29], which revealed some regulatory motifs previously found in most eukaryotic promoters (Fig. 1 and Table 1). For instance, the following sequence features were found: one W box, four TGACG motifs, one $\mathrm{S}$ box, four binding sites of MYB transcription factor, TC-rich repeat, one TGA-element involved in response to auxin and one ARE element involved in response to anaerobic conditions. In addition, motifs responsible for tissue-specific gene expression or expression that is 


\section{-2120 bp}

GTCGCAGATATATAAACACTCCCGTGATTTTACGAGCACCTAAACTAGTTAGTATGTATAACTATTTAGTAGCTTAAATTAATGGA 5'UTR Py-rich stretch GGAAAAATTAT AGAGTAGAAATTAAAGCGTGACAAGGTCTAGTAAATGGGCTCATTTTGGGCCACTCAGCTTTGAACCCCTTAAT GATTGGGCAGCTCATCTATAAAATGAACATGTTTTGGAATGGTGATGCTGCACGAGAGTACTAGAATACTACATAGATAAATGAC TGACG-motif ATTGAAATTATCACATTATTTACATCGTCTATTACTGTACATTTTATTACTATGACTCACAAACTTATTACAATTATTAAATTT

GT1-motif TGACG-motif

ATACTTATTTTCCTTATGGGTTCATACGGGTGATGGCCATCTTAAGCAGCGACATTTTTTTGTGTTAACCA IGACGCCAATGAA

Skn-1 motif CATGAGTATTCCATACGCTAAACTAGTTTACCCAAGATGGAGGACAATTCTTGAACTCATCCTTCGATAGTCATTAATGACCACCT TGACG-motif
TAAA [GACGACATATACAAGTCAAGGCTCAAGAAGATATAAGATCACGACTCTAAACCATAATAACTAAGGACTTGTCCATATCA GTGTATCACCACCTTAGATAGCGACTTTTTCACGTTGCCTTTTAAGATGAAAACTTCTAGCTAAGTGTACTAATCAAGAAAACGAT CTTCTTTAAAGAGTATAATTAATTATAACGGGTTTGATAGAAAGATACTTAACAAAATCGTCCATACTAAAATAATCTTTCACAAT MRE AATAATGGAACCTAAACTTAGGTGTACTATGCAATTACTTTACAAATCGATTAATTTTTTTTTCCTTTAACTTCTTTTAAAAGTACA TTCGTGGAGGATATGTTTTAATTTGTCCCTAATTATCCTTATTATGCTTTACTAGAATACGTTAACAGGCCTTTATCTTTTCCGCCTT TC-rich repeats -1149 bp CATITCCTICA TGCTTCTTTTGATGAAA Skn-1 motif CAAGCAAACTAGTAATATACTCAATTAGGAGAAATGTCATCAAAAGAAACTCCTGATATAAAGTGTGAGAATTTTTAGCATATGT TCATTTTACAATCCAATTAATAGATTTGAGGTTGATTTTCGTTTTATTCACAACTGATTTAATTGCAATTTCGCTTATTACGTAGR-1_motif ATTTTATTATTTCTGCCTCTCTTTTATTAGACATTATTAGTTTTTTTTTATTATTATAGTCAGATCTACGATAATTGTTAAGAATATG -822 bp

ATGTACCAACGTGAGTAACTATAGCACGCCGGTTTAAATCTAAAACAAAGGTAGATACTTGTGGCAATTCATCAGGCTGTGTGTT G-box AC1
GGTCCCACATACCGACACT 1 motif ATTAAATGGACAATGCTATGGGGACACCCATTTTCATAAGATTAAAATAATATTTCTCATTTCTAGGGTCTACCACAAATAAAAGC AATATTTTAAAATTATGTGAATGGTGTCACCGGGAATTAGTGAGACATGGTGGCGCC PCATCATTICGAACTTAAATTGCTTTGG ATTCTCATGTCTAACTATGCAAACATAAAGGTATGTTGTCACAATAACTTGTTCTAGATTTTCAATAAGACGATCATTAGTTTGCG

GT1-motif TGAGCCGTAGAGCATCGTCTATAAATTCCAACATCACCTTGTGATAAACAATCTCAATAATACATTTTAACCAAATCACCCGATAA Skn-1_motif $\quad \mathbf{- 2 9 0}$ bp CACTTTGTCATTATATCTGTACTCTATAGCCTTTATCTTATCTCGTTAACAACAATGAGACAAATGTGAGTTGAGTGTATCCGTATA

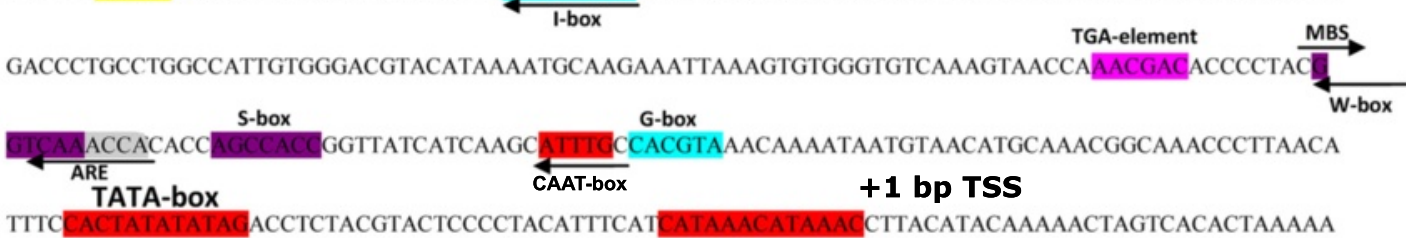
TCAAGTGAAAATG

Fig. 1 The nucleotide sequence of $5^{\prime}$-flanking promoter region of pro-SmAMP2 gene and location of cis-acting elements (color-coded and labeled). Vertical arrows mark the starting points of the $5^{\prime}$-deletion variant nucleotide sequences. TSS is the transcription start site at -40 bp from ATG codon behind the region highlighted in red. Translation initiation site ATG +41 is labeled in italics 
Table 1 Motifs detected in pro-SmAMP2 gene promoter sequence (based on the results of analysis by PLACE and PlantCARE programs)

\begin{tabular}{|c|c|}
\hline Motif & Description \\
\hline 5UTR Py-rich stretch & $\begin{array}{l}\text { region in the } 5 \text { primeUTR conferring high } \\
\text { transcription levels without the need for } \\
\text { other upstream cis-elements except for } \\
\text { a TATA-box }\end{array}$ \\
\hline GCN4_motif & $\begin{array}{l}\text { cis-regulatory element involved in } \\
\text { endosperm expression }\end{array}$ \\
\hline TGACG-motif, CGTCA-motif & $\begin{array}{l}\text { cis-acting regulatory element involved } \\
\text { in the MeJA-responsiveness }\end{array}$ \\
\hline GT1-motif & light responsive element \\
\hline $\begin{array}{l}\text { ARE (anaerobic responsive } \\
\text { element) }\end{array}$ & $\begin{array}{l}\text { cis-acting regulatory element essential } \\
\text { for the anaerobic induction }\end{array}$ \\
\hline MRE & $\begin{array}{l}\text { MYB binding site involved in light } \\
\text { responsiveness }\end{array}$ \\
\hline ACE & $\begin{array}{l}\text { cis-acting element involved in light } \\
\text { responsiveness }\end{array}$ \\
\hline TC-rich repeats & $\begin{array}{l}\text { cis-acting element involved in defense } \\
\text { and stress responsiveness }\end{array}$ \\
\hline Skn-1_motif & $\begin{array}{l}\text { cis-acting regulatory element required } \\
\text { for endosperm expression }\end{array}$ \\
\hline MBS & $\begin{array}{l}\text { MYB binding site involved in drought- } \\
\text { inducibility }\end{array}$ \\
\hline G-box & $\begin{array}{l}\text { cis-acting regulatory element involved } \\
\text { in light responsiveness }\end{array}$ \\
\hline$A C-1$ & $\begin{array}{l}\text { element involved in negative regulation } \\
\text { on phloem expression; and responsible } \\
\text { for restricting the vascular expression to } \\
\text { the xylem }\end{array}$ \\
\hline TCA-element & $\begin{array}{l}\text { cis-acting element involved in salicylic } \\
\text { acid responsiveness }\end{array}$ \\
\hline I box & part of a light responsive element \\
\hline TGA-element & auxin-responsive element \\
\hline W-box & wounding and pathogen elicitor response \\
\hline S box & wounding and pathogen elicitor response \\
\hline CAAT-box & $\begin{array}{l}\text { common cis-acting element in promoter } \\
\text { and enhancer regions }\end{array}$ \\
\hline TATA-box & $\begin{array}{l}\text { core promoter element around }-30 \text { of } \\
\text { transcription start }\end{array}$ \\
\hline
\end{tabular}

invoked in response to the light conditions are present in the nucleotide sequence of the promoter region. Amongst these, were one GCN4 motif and four Skn-1 motifs, both of which are associated with increased expression in the endosperm of seeds, one AC-I motif associated with increased expression in the xylem, one I box, two GT1 motifs and two $\mathrm{G}$ box elements, all related to LRE elements responsible for expression in above-ground parts and regulated by light exposure. The presence of such motifs suggests that the activity of the pro-SmAMP2 gene in chickweed plant can be regulated by the interaction of different transcription factors with the corresponding cis-elements within the promoter. Moreover, the pro-SmAMP2 gene promoter contains the conservative sequence of
TATA-box CATTTCCACTATATATAG, CAAT-box motif and the transcription initiation site $\mathrm{CAN}(\mathrm{A} / \mathrm{C})(\mathrm{A} / \mathrm{C})(\mathrm{C} /$ A) $C(C / A) N_{2} A(C / A)$. Altogether, this analysis suggests that pro-SmAMP2 promoter is strong and potentially regulated in response to stress, as for example, pathogen attack and/ or light exposure.

The sequence of the pro-SmAMP2 promoter region shown in Fig. 1 also includes the 5'-UTR of pro-SmAMP2 gene, which was only $40 \mathrm{bp}$ in the $5^{\prime}$ direction from the translation initiation site ATG.

In order to study the properties of the pro-SmAMP2 gene promoter related to the expression of genes in heterologous systems, six genetic constructs, containing various $5^{\prime}$-deletion variants of the promoter region with 5'UTR, were obtained (see Methods and Fig. 2).

Deletion variants of the pro-SmAMP2 promoter region were chosen in such a way that the location of cis-regulatory elements in the nucleotide sequence was taken into account. The plasmid pMOG-35SintGus, in which the gus gene is controlled by the CaMV $35 S$ viral promoter, was used as a positive control. In the vectors, modified castor bean catalase intron or ST-LS1 gene intron was placed within the sequence of the gus gene (Fig. 2) to prevent the influence of Agrobacterium contamination on the results of GUS activity measurements in transformed plants.

Pro-smAMP2 promoter yields higher GUS activity in $\mathrm{T}_{0}$ transgenic tobacco plants than the CaMV $35 S$ promoter After Agrobacterium-mediated transformation, independent $\mathrm{T}_{0}$ tobacco plants, each taken from individual calli, were selected in the following number: $\mathrm{T}_{0} \mathrm{p} 2120-10$ plants, $\mathrm{T}_{0} \mathrm{p} 1504-9$ plants, $\mathrm{T}_{0} \mathrm{p} 1149$ - 12 plants, $\mathrm{T}_{0} \mathrm{p} 822$ -

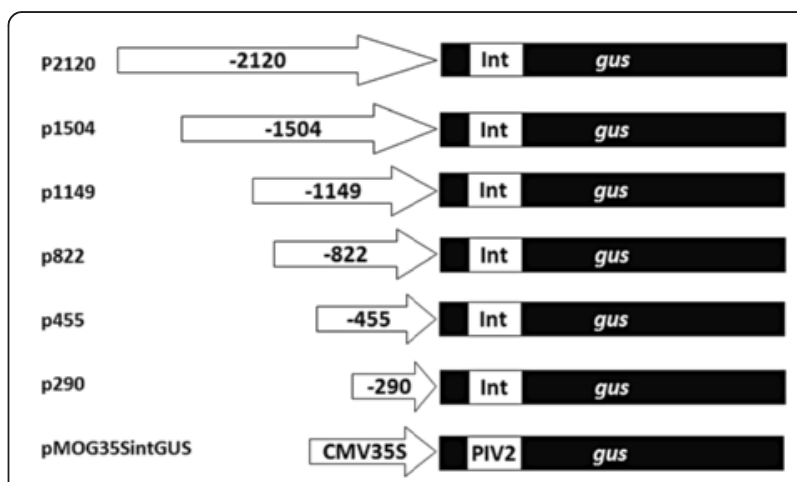

Fig. 2 The scheme of constructs with deletion variants of pro-SMAMP2 gene promoter region designed on basis of plant expression vector pCambia $1381 \mathrm{Z}$ for analysis of gus reporter gene expression. Plant expression vector pMOG-35SintGUS containing CaMV 355 viral promoter was used as a control. The translated region of gus gene is colored black; Int - modified castor bean catalase intron within the translated region of gus gene; PIV2 - modified potato ST-LS1 gene intron within the translated region of gus gene. Promoters are depicted as arrows with the appropriate signatures 
13 plants, $\mathrm{T}_{0} \mathrm{p} 455$ - 8 plants, $\mathrm{T}_{0} \mathrm{p} 290$ - 22 plants, and control $\mathrm{T}_{0}$ pMOG-35SintGus - 15 plants. Estimation of the GUS activity in protein extracts from leaves of aseptic transgenic plants showed that all deletion variants of the pro-SmAMP2 promoter except -290 bp (Additional file 1: Table S1) expressed the gus gene.

In most transgenic plants from groups $\mathrm{T}_{0} \mathrm{p} 1504$, $\mathrm{T}_{0} \mathrm{p} 1149, \mathrm{~T}_{0} \mathrm{p} 822$ and $\mathrm{T}_{0} \mathrm{p} 455$, the GUS activity ranged from 2 to $20 \mathrm{nmol} / \mathrm{mg}$ · min. This was several times higher than the GUS activity measured in the control plants $\mathrm{T}_{0} \mathrm{pMOG}-35$ SintGus, ranging from 0.2 to $1.8 \mathrm{nmol} / \mathrm{mg}$. min (Fig. 3a). The level of GUS activity in $\mathrm{T}_{0} \mathrm{p} 2120$ plants was comparable to plants expressing gus under the control of $C a M V 35 S$ promoter, and did not exceed $1.8 \mathrm{nmol} / \mathrm{mg}$. min (Fig. 3a). Differences in GUS activity levels amongst independent primary transformants of different constructs is most probably due to the integration of multiple T-DNA copies into their genome or chimerism.

Similar to the measurements in aseptic plants, GUS enzymatic activity was analyzed in the tobacco leaves of $\mathrm{T}_{0}$ plants, grown in soil. First, Fig. 3b shows that the maximum levels of GUS activity in leaves of $\mathrm{T}_{0}$ transgenic tobacco plants grown in the soil were notably higher than the values obtained for the same plants under aseptic conditions. On average, GUS activity values of $180 \mathrm{nmol} / \mathrm{mg}$. $\min$ in $\mathrm{T}_{0} \mathrm{p} 2120,150 \mathrm{nmol} / \mathrm{mg} \cdot \min$ in $\mathrm{T}_{0} \mathrm{p} 1504,70 \mathrm{nmol} /$ $\mathrm{mg} \cdot \mathrm{min}$ in $\mathrm{T}_{0} \mathrm{p} 1149,84 \mathrm{nmol} / \mathrm{mg} \cdot \mathrm{min}$ in $\mathrm{T}_{0} \mathrm{p} 822$, and $31 \mathrm{nmol} / \mathrm{mg} \cdot \min$ in $\mathrm{T}_{0} \mathrm{p} 455$ were observed. However, a 5

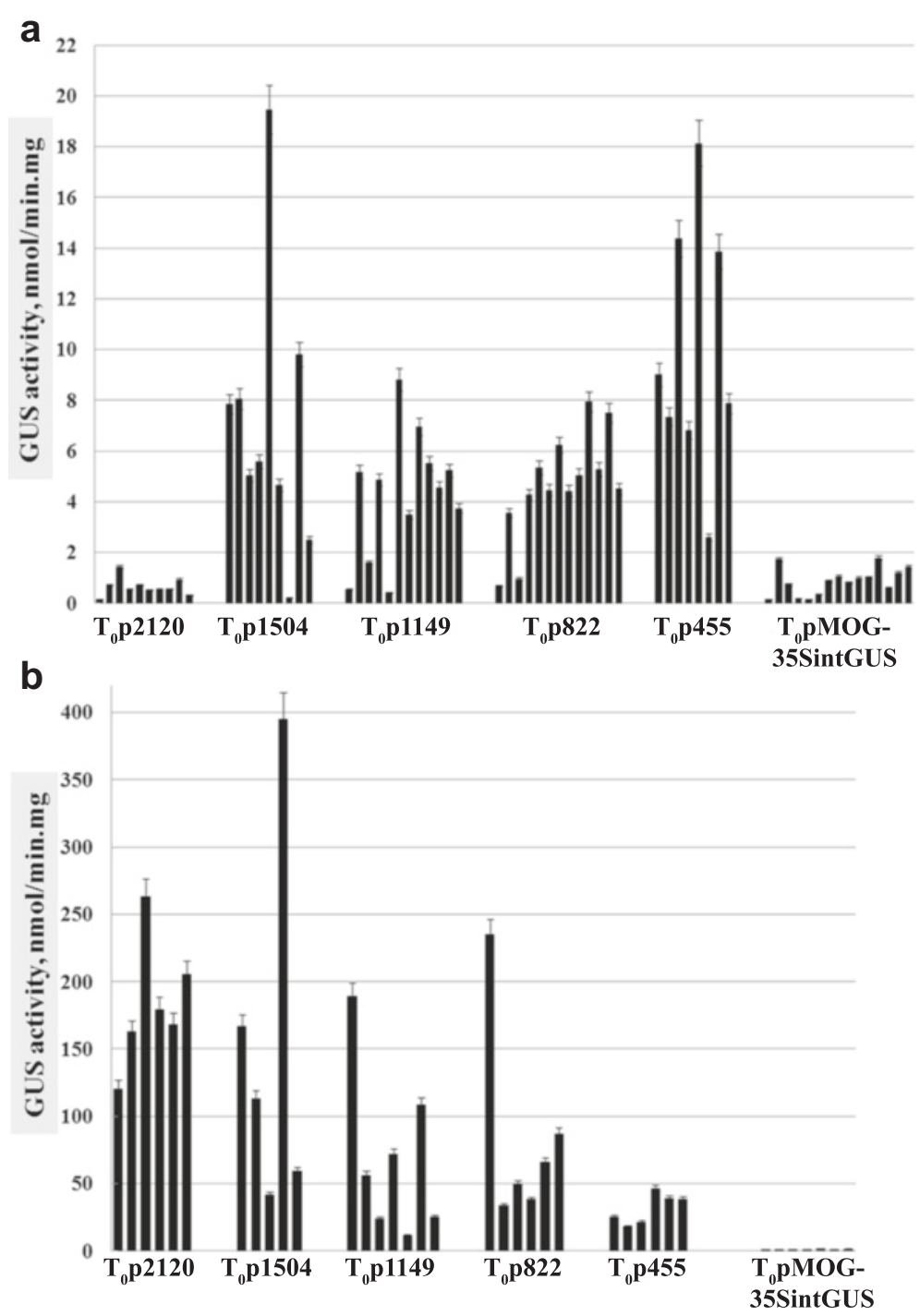

Fig. 3 The GUS activity in tobacco transformants $T_{0}$. a Plants were growing under aseptic conditions 1.5 months after rooting on the medium with a selective agent. The average values of activity from three mature leaves of each transformant \pm SE (the standard error) are presented. b Plants were grown for six weeks in soil after being transplanted from aseptic conditions. The average activity values of three samples from one leaf of each transformant \pm SE are presented 
to 10-fold difference was detected between some of the individual $\mathrm{T}_{0} \mathrm{p} 1504, \mathrm{~T}_{\mathrm{O}} \mathrm{p} 1149$ and $\mathrm{T}_{\mathrm{O}} \mathrm{p} 822$ plants. Secondly, unlike under aseptic conditions, in average, the highest GUS activity of plants grown in soil was observed in $\mathrm{T}_{\mathrm{O}} \mathrm{p} 2120$ plants. Thirdly, decreasing the length of the proSmAMP2 promoter resulted in a decrease in GUS activity. In the CaMV $35 S$ plants the average GUS activity was not higher than $1.2 \mathrm{nmol} / \mathrm{mg}^{*} \mathrm{~min}$. It should be noted that the GUS activity of the $\mathrm{T}_{\mathrm{o}}$ pMOG-35SintGus plants grown in soil was also slightly (1.5 to 2 -fold) higher than in the aseptically grown plants.

The highest levels of GUS activity was measured in leaves of tobacco plants $\mathrm{T}_{\mathrm{O}} \mathrm{p} 2120$ (5 transformants), $\mathrm{T}_{\mathrm{op}} 1504$ (2 transformants), $\mathrm{T}_{0} \mathrm{p} 1149$ (2 transformants), $\mathrm{T}_{0} \mathrm{p} 822 \quad(2$ transformants) and $\mathrm{T}_{0} \mathrm{p} 455$ (5 transformants) growing in soil (Fig. 3b). GUS activity in the adventitious roots and flowers of the same plants was less than $20 \%$ of the activity in leaves and ranged 2 to 5 -fold between samples of one transgene version. GUS activity in stems of individual primary transformants $\mathrm{T}_{0} \mathrm{p} 455$ (young sprouts $8-10 \mathrm{~cm}$ long) could be at the level of activity in leaves but it varied 2 to 4fold from plant to plant. GUS activity in stems of other transgenic lines $\mathrm{T}_{\mathrm{o}} \mathrm{p} 2120, \mathrm{~T}_{\mathrm{o}} \mathrm{p} 1504, \mathrm{~T}_{\mathrm{o}} \mathrm{p} 1149$ and $\mathrm{T}_{\mathrm{o}} \mathrm{p} 822$ was not higher than $25 \%$ of activity in leaves and it also varied greatly from plant to plant (Additional file 2: Fig. S1).

\section{Pro-SmAMP2 promoter retains its activity in the progeny of $\mathrm{T}_{1}-\mathrm{T}_{3}$ transgenic plants}

The level of GUS activity in the progeny of $\mathrm{T}_{0}$ transgenic plants was studied to characterize the properties of proSmAMP2 promoter deletion variants across the generations. For that, seeds of $\mathrm{T}_{1}$ from five transgenic tobacco plants of each group $\mathrm{T}_{\mathrm{o}} \mathrm{p} 2120, \mathrm{~T}_{\mathrm{o}} \mathrm{p} 1504, \mathrm{~T}_{\mathrm{O}} \mathrm{p} 1149, \mathrm{~T}_{\mathrm{o}} \mathrm{p} 822$ and $\mathrm{T}_{0} \mathrm{p} 455$ expressing gus gene were produced by selfpollination. At least 200 seeds from each $\mathrm{T}_{0}$ plant representing one population were aseptically planted on selective medium containing the antibioticum hygromycin. After 4 weeks of selection, segregation of plants into the subpopulations of transgenic $\mathrm{T}_{1}$ (green) and non-transgenic (whitened) was analyzed. In some populations from groups $\mathrm{T}_{1} \mathrm{p} 2120, \mathrm{~T}_{1} \mathrm{p} 1504, \mathrm{~T}_{1} \mathrm{p} 1149, \mathrm{~T}_{1} \mathrm{p} 822$ and $\mathrm{T}_{1} \mathrm{p} 455$, a segregation ratio of 3:1 between green and white plants was confirmed using the Chi-square criterion which is consistent with the presence of T-DNA at a single locus of the genome. These results, however, do not allow an estimate of the number of T-DNA repeats at such insertion locus.

In some $T_{1}$ populations the segregation ratio was different from monogenic being equal to $2: 1$, probably as a result of elimination of one transgenic class. There were also $T_{1}$ populations with a segregation ratio of 15:1, which suggests the presence of T-DNA in two unlinked loci of the ancestral $\mathrm{T}_{0}$ plant genome.

Enzymatic activity of GUS protein was studied in $\mathrm{T}_{1}$ plants with all deletion variants $\mathrm{T}_{1} \mathrm{p} 2120, \mathrm{~T}_{1} \mathrm{p} 1504, \mathrm{~T}_{1} \mathrm{p} 1149$,
$\mathrm{T}_{1} \mathrm{p} 822$ and $\mathrm{T}_{1} \mathrm{p} 455$ to determine the level of the reporter gene gus expression. As shown in Fig. 4a, high GUS activity was still present in $\mathrm{T}_{1}$ transgenic tobacco plants carrying all deletion variants of the pro-SmAMP2 promoter. Two-fold difference in levels of GUS activity between individual transgenic plants from the same $T_{1}$ population with monogenic segregation observed in all variants most probably resulted from their T-DNA locus being homoor heterozygotic (Fig. 4a). The difference in GUS activity between different populations with monogenic inheritance of $\mathrm{T}_{1} \mathrm{p} 1149, \mathrm{~T}_{1} \mathrm{p} 822$ and $\mathrm{T}_{1} \mathrm{p} 455 \mathrm{~T}$-DNA could result from the integration of two T-DNA copies into one chromosome locus or from the positional effect of T-DNA insertion (Fig. 4a).

The GUS activity level was significantly lower in all $\mathrm{T}_{1}$ transgenic plants compared to the progenitor $\mathrm{T}_{0}$ plants. The highest reduction (more than 25-fold) was observed in the $\mathrm{T}_{1} \mathrm{p} 2120$ plants. The activity decreased 8 - to 11 fold in $\mathrm{T}_{1} \mathrm{p} 1504, \mathrm{~T}_{1} \mathrm{p} 1149, \mathrm{~T}_{1} \mathrm{p} 822$, and 3 to 5 -fold in $\mathrm{T}_{1} \mathrm{p} 455$ plants. Thus, the longer the nucleotide sequence of the promoter deletion variant, the greater the reduction in GUS activity in $\mathrm{T}_{1}$ plants compared to the progenitor $\mathrm{T}_{0}$ plants.

Nevertheless, even the level of GUS activity in transgenic $\mathrm{T}_{1}$ plants of the efficient deletion variants of the pro-SmAMP2 promoter region was equal to or several times higher than the activity achieved with the CaMV $35 S$ promoter $\left(0.9-3.3 \mathrm{nmol} / \mathrm{mg}^{\cdot m i n}\right.$ in $[12,30]$ and $10 \mathrm{nmol} / \mathrm{mg} \cdot \min$ in [25]).

For $\mathrm{T}_{2}$ generation studies, only transgenic plants with the longest $-2120 \mathrm{bp}$ and the shortest $-455 \mathrm{bp}$ deletion variants of pro-SmAMP2 promoter were used. High GUS activity was preserved in transgenic tobacco plants of $\mathrm{T}_{2}$ generation with deletion variants -2120 and -455 bp of pro-SmAMP2 promoter (Fig. 4b). In two independent $\mathrm{T}_{2} \mathrm{p} 2120$ populations, No. 8-2 and No. 19-1, all transgenic plants were resistant to the selective agent hygromycin and did not differ significantly in the level of GUS activity from each other, what indicates that they are homozygous for the T-DNA locus. The average GUS activity level in the population No. 19-1 and No. 82 was $9.0 \pm 0.4 \mathrm{nmol} / \mathrm{mg} \cdot \mathrm{min}$ and $10.9 \pm 1.7 \mathrm{nmol} / \mathrm{mg} \cdot \mathrm{min}$ respectively, which corresponds to the activity in their parent $\mathrm{T}_{1}$ plants (Fig. 4a).

Unlike transgenic plants $\mathrm{T}_{2} \mathrm{p} 455$ No. 14-3, all of which were resistant to hygromycin, the plant population No. 10-8 segregated in the ratio of $3: 1$ for resistance to hygromycin (Fig. 4b). These results show that plants of $\mathrm{T}_{2} \mathrm{p} 455$ population No. $10-8$ were obtained from $\mathrm{T}_{1}$ generation plants hemizygous for T-DNA locus. The average level of activity in plants of the population No. $14-3$ was about $17.4 \pm 1.8 \mathrm{nmol} / \mathrm{mg} \cdot \mathrm{min}$, that is about 1.3 times higher than the average level in the population $\mathrm{T}_{2} \mathrm{p} 455$ No. $10-8$, being $13.1 \pm 2.7 \mathrm{nmol} / \mathrm{mg}$. 

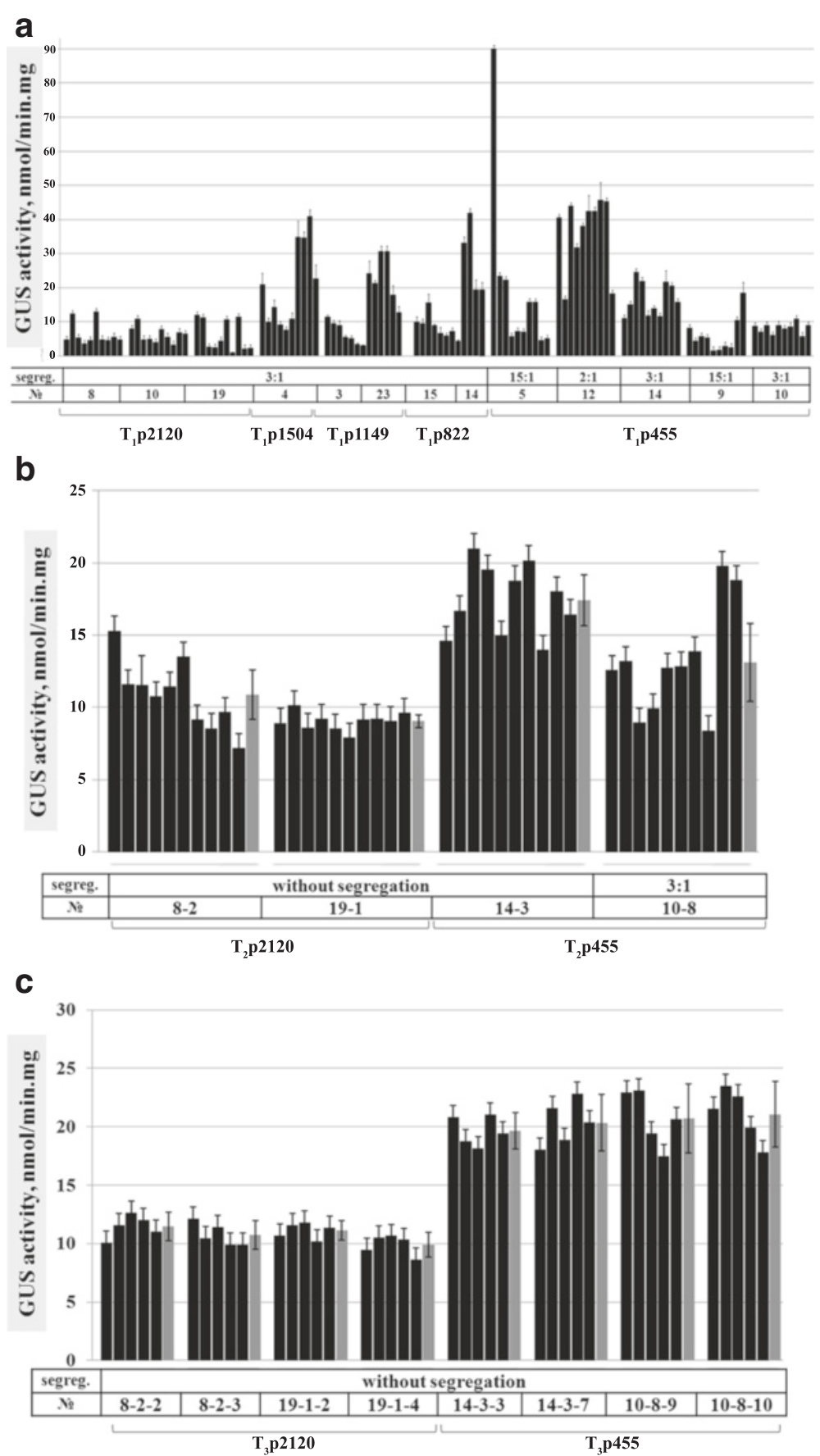

Fig. 4 The GUS activity in leaves of transgenic tobacco plants from three consecutive generations $(T 1, T 2, T 3)$ measured in six weeks of growth in soil after transplanting from aseptic conditions. The average activity values of three samples from one leaf of each transformant \pm SE are presented. The average activity among the plants of one population \pm confidence interval $(p=5 \%)$ are shown as gray bars. a $T_{1} \cdot \mathbf{b} \mathrm{T}_{2} \cdot \mathbf{c} \mathrm{T}_{3}$

min (Fig. 4b). At the same time, activity levels were close in plants $\mathrm{T}_{2} \mathrm{p} 455$ No. $14-3$ and in two plants from populations No. 10-8 with the highest activity, which, as we assume, were homozygous for T-DNA loci. In order to confirm this we produced and analyzed $\mathrm{T}_{3}$ generation. Two plants with GUS activity 2-fold higher than the other plants from the population $\mathrm{T}_{2} \mathrm{p} 455$ No. $10-8$ were used to generate $\mathrm{T}_{3}$ (Fig. $4 \mathrm{~b}$ ).

High GUS activity was preserved in $\mathrm{T}_{3}$ generation transgenic tobacco plants on the level of their parent plants $\mathrm{T}_{2}$ with pro-SmAMP2 promoter deletion variants -2120 and -455 bp (Fig. 4b and c). All transgenic 
plants were resistant to hygromycin and had comparable level of GUS activity in individual plants, which suggested their homozygous state for T-DNA loci. The average level of GUS activity in $\mathrm{T}_{3} \mathrm{p} 455$ populations was as high as 19.6 $\pm 1.6 \mathrm{nmol} / \mathrm{mg} \cdot \min$ in No. $14-3-3,20.3 \pm 2.4$ in No. 14-3-7, $20.7 \pm 3.0$ in No. $10-8-9$ and $21.1 \pm 2.8$ in No. $10-8-10$. The average level of GUS activity in $\mathrm{T}_{3} \mathrm{p} 2120$ populations was $11.5 \pm 1.2 \mathrm{nmol} / \mathrm{mg} \cdot \mathrm{min}$ in No. 8-2-2, $10.8 \pm 1.2$ in No. 8$2-3,11.1 \pm 0.8$ in No. $19-1-2$ and $9.9 \pm 1.1$ in No. 19-1-10.

Southern blotting analysis showed that $\mathrm{T}_{3}$ p2120 plants from population No. 8-2-2 and $\mathrm{T}_{3} \mathrm{p} 455$ plants from population No. 14-3-3 contain T-DNA insertion at one genomic locus (Fig. 5). Consequently, GUS activity levels achieved in these plants was provided by a single locus T-DNA insertion.

\section{GUS activity changes during vegetative period in} homozygous $\mathrm{T}_{3}$ lines with pro-SmAMP2 promoter deletion variants -2120 and -455 bp under different light conditions

In previous experiments, the level of GUS activity was measured in transgenic plants of $\mathrm{T}_{1}-\mathrm{T}_{3}$ generations at the age of approximately 70 days. However, the dynamics of GUS activity in leaves of homozygous transgenic plants during the growth season is not known. In addition, the effect of the length of the light period on pro-SmAMP2 promoter activity in heterologous plants was also not clear. As the pro-SmAMP2 promoter contains regulatory elements potentially able to change its activity in dependence of the light condition (Fig. 1 and Table 1), we studied GUS activity under different light regimes.

For this purpose, homozygous tobacco plants from transgenic lines $\mathrm{T}_{3} \mathrm{p} 2120$ (No. 8-2-2 and No. 19-1-2) and

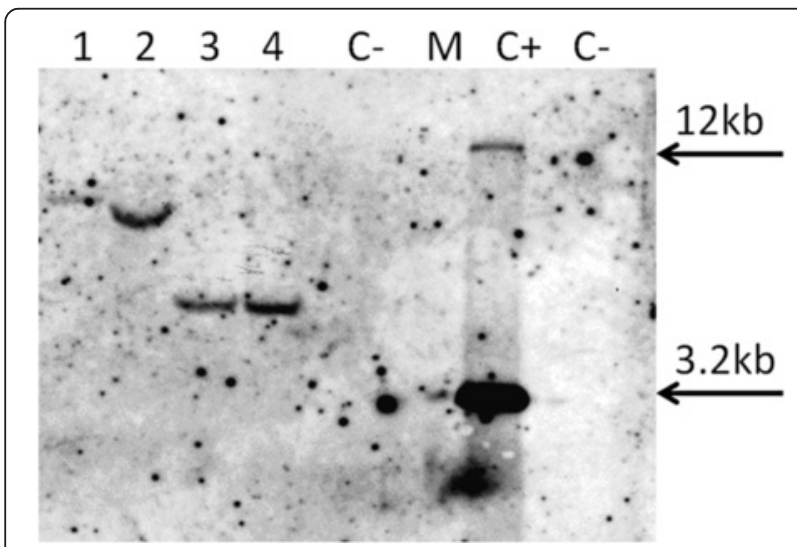

Fig. 5 Southern blotting analysis of total DNA from leaves of two plants $\mathrm{T}_{3}$ p2120 No. 8-2-2 (lanes 1 and 2) and T3p455 No. 14-3-3 (lanes 3 and 4) restricted with ECORI. "C-"- total DNA from leaves of non-transgenic tobacco plants restricted with EcoRI. M - marker (Fermentas, \#Sm333). "C+" - plasmid pMOG-35SintGus restricted with HindIII. The 740 bp fragment of gus gene was used as probe
$\mathrm{T}_{3}$ p455 (No. 14-3-3 and No. 10-8-9), were grown at short and long day, bypassing the selection stage on the medium with hygromycin. Data from Fig. 6 suggest that GUS activity was higher under long-day (16/8 h) than under short-day $(12 / 12 \mathrm{~h})$ condition on days $51,58,72$ and 80 in $\mathrm{T}_{3} \mathrm{p} 2120$ plants, and from day 51 to 65 in $\mathrm{T}_{3} \mathrm{p} 455$ plants. However, these differences were not significant ( $p=5 \%)$, except for day 72 in $\mathrm{T}_{3} \mathrm{p} 2120$.

Under long-day condition, GUS activity level was at least 1.5 times higher $(p=5 \%)$ in $\mathrm{T}_{3} \mathrm{p} 455$ than in $\mathrm{T}_{3}$ p2120 plants for the entire observation period (Fig. 6). The same trend was detected under short-day condition, except days 37 and 65 when the differences between $\mathrm{T}_{3} \mathrm{p} 455$ and $\mathrm{T}_{3} \mathrm{p} 2120$ were not significant $(p=5 \%)$.

Figure 6 also shows that a GUS activity of $9-11 \mathrm{nmol} /$ $\mathrm{mg} \cdot \mathrm{min}$ in $\mathrm{T}_{3} \mathrm{p} 2120$ and $16-19 \mathrm{nmol} / \mathrm{mg} \cdot \mathrm{min}$ in $\mathrm{T}_{3} \mathrm{p} 455$ plants, grown in the soil directly from seed, was reached on day 51, but not on day 70 as was observed for those plants, selected on the medium with hygromycin (Fig. 4c). In the subsequent days, GUS activity increased and reached on day $8022-29 \mathrm{nmol} / \mathrm{mg} \cdot \mathrm{min}$ in $\mathrm{T}_{3} \mathrm{p} 2120$ and 53-54 $\mathrm{nmol} / \mathrm{mg} \cdot \mathrm{min}$ in $\mathrm{T}_{3} \mathrm{p} 455$ (Fig. 6). In plants with the pro-SmAMP2 promoter deletion variant $-455 \mathrm{bp}$, GUS activity on day 80 was comparable to that previously measured in the primary transformants growing in soil (Fig. 3b). Measurements on day 87 showed that GUS activity decreased: more in $\mathrm{T}_{3} \mathrm{p} 2120$ and less in $\mathrm{T}_{3} \mathrm{p} 455$ plants (Fig. 6).

\section{GUS activity correlates with the content of gus gene mRNA in transgenic plants $T_{3}$ p2120 and $T_{3}$ p455}

The results of real-time PCR measurement of gus gene expression relative to the actin reference gene of tobacco are shown in Fig. 7a. It can be concluded from the data that: 1) gus expression was higher than actin gene expression in almost all transgenic plants, and 2) on average, gus gene mRNA content was two times higher in the samples from $\mathrm{T}_{3} \mathrm{p} 455$ than from $\mathrm{T}_{3} \mathrm{p} 2120$ plants.

Strong positive correlation $(r=0.9 \pm 0.11)$ between GUS activity levels and gus gene mRNA expression was shown in the leaves of $\mathrm{T}_{3} \mathrm{p} 455$ and $\mathrm{T}_{3} \mathrm{p} 2120$ plant variants analyzed together as a pooled set (Fig. 7b). The correlation coefficient for $\mathrm{T}_{3} \mathrm{p} 455$ plants taken separately $\left(r_{455}=0.76 \pm 0.26\right)$ also supported the strong relationship between gus gene mRNA content and the activity of its protein product, while the correlation was not that strong in the $\mathrm{T}_{3} \mathrm{p} 2120$ variant $\left(r_{2120}=0.44 \pm 0.36\right)$.

When analyzed in a pooled group, activity of the GUS protein per unit of gus gene mRNA changed linearly with a regression coefficient of $b=2.37 \pm 0.30$ (Fig. 7b). This parameter did not differ significantly between separate $\mathrm{T}_{3} \mathrm{p} 455\left(b_{455}=2.44 \pm 0.85\right)$ and $\mathrm{T}_{3} \mathrm{p} 2120\left(b_{2120}=\right.$ $1.0 \pm 0.84)$ groups due to large statistical variation. 


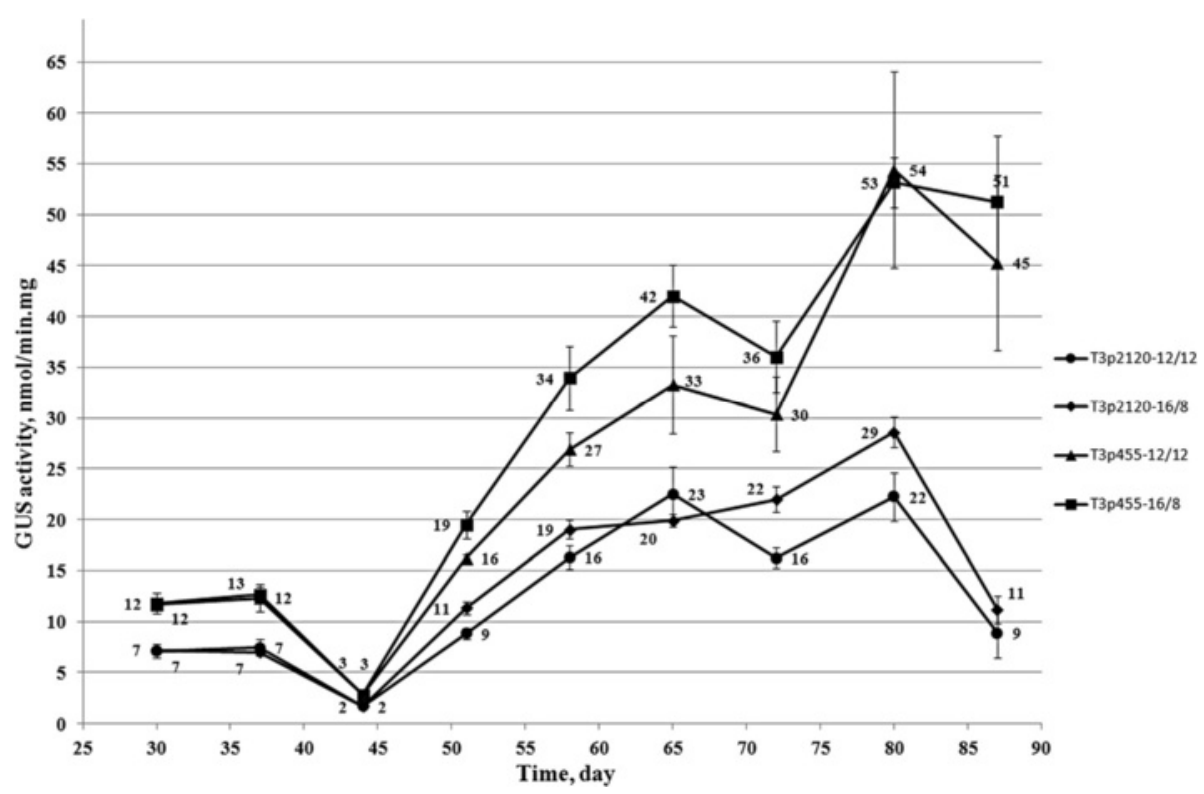

Fig. 6 The GUS activity in the leaves of $T_{3}$ generation homozygous transgenic tobacco plants grown in soil from seeds. Eight plants were studied under long day $(16 / 8 \mathrm{~h})$ and six plants under short day $(12 / 12 \mathrm{~h})$ conditions for both variants $\mathrm{T}_{3} \mathrm{p} 2120$ and T3p455. The average levels of GUS activity in adjacent leaves from medium tiers \pm SE are presented

Pro-SmAMP2 promoter is active in different organs and at different stages of $\mathrm{T}_{3} \mathrm{p} 2120$ and $\mathrm{T}_{3} \mathrm{p} 455$ development

Staining showed that activity of both pro-SmAMP2 promoter deletion variants is present in leaves, stems, roots, buds, anthers, microsporocytes and pollen. Particularly intense staining was noted in the hypocotyl of all transgenic plants, which indicates a higher activity of the proSmAMP2 promoter region in this part of a plant (Fig. $8 \mathrm{a}$ ). The least intense staining of leaves present in transgenes was typical for the youngest apical ones.

Histochemical analysis allowed us to conclude that the pro-SmAMP2 promoter is active not only in plant cells at the stage of sporophyte but also during meiosis and at the stage of gametophyte, as GUS activity was detected in the microsporocytes and pollen (Fig. 8d, f).

At the same time, a high level of GUS activity in all studied organs and cells of transgenic plants did not allow to visually identify differences between the $T_{3}$ p2120 and $\mathrm{T}_{3} \mathrm{p} 455$ variants. Moreover, in some transgenic plant samples subjected to the histochemical analysis, products of X-Gluc substrate hydrolysis stained not only the plants themselves but also the incubation solutions, that indicates that the levels of GUS protein in these samples is very high. It was also noted that if the plant tissue was damaged, solution staining was more intense.

Quantitative method of GUS activity assay using 4MUG substrate was used for comparative analysis of proSmAMP2 promoter deletion variants activity in $\mathrm{T}_{3}$ seeds obtained from $\mathrm{T}_{2} \mathrm{p} 2120$ and $\mathrm{T}_{2} \mathrm{p} 455$ tobacco plants. The activity from 1.2 to $19.8 \mathrm{nmol} / \mathrm{mg}^{*}$ min was detected in $\mathrm{T}_{3}$ seeds, but it varied strongly even between plants from the same line. This finding was quite surprising, because in chickweed plants, the pro-SmAMP2 gene promoter ensures the accumulation of antifungal peptides SmAMP1.1a and SmAMP2.2a in seeds [26].

\section{Discussion}

In previous studies, we established that pro-SmAMP2 gene expression in chickweed was at a very high level comparable with the level of actin gene expression, and the highest values were observed in the roots and flowers of plants [26]. In addition, pro-SmAMP2 gene expression in aseptic chickweed plants increased from two to five times due to the contact with phytopathogenic fungi, as well as after methyl jasmonate treatment. The combination of these results suggests that the pro-SmAMP2 gene promoter is strong, slightly inducible and organ-specific in chickweed. The properties of the pro-SmAMP2 gene promoter region in chickweed plant are determined by two factors, namely, the presence of specific regulatory elements in its nucleotide sequence, as well as the presence and activity of respective transcription factors within the plant cells.

It is known that the promoters of PR-protein genes are usually strong [24], and the location of specific motifs such as CATTTCCACTATATATAG, CAAT-box, CATAAACATAAAC in the promoter core segment confirms this. Such motifs are found in promoters of plant genes with high expression level [31]. The nucleotide sequence of the pro-SmAMP2 gene promoter region 


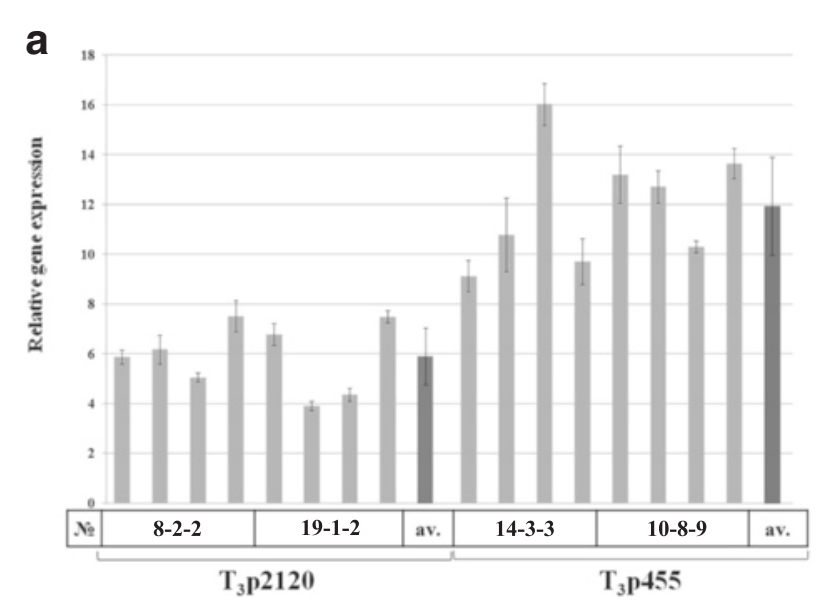

b

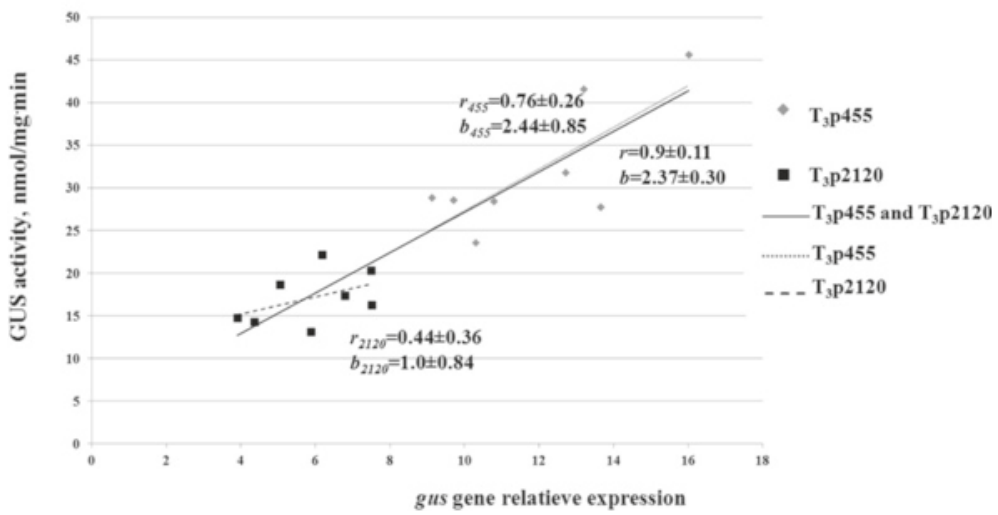

Fig. 7 Gus gene expression in leaves of $T_{3}$ p2120 and $T_{3}$ p455 tobacco plants measured by real-time PCR. a Gus gene expression normalized to the expression of actin gene. Average values for individual transgenic plants \pm SE are presented as gray bars. For transgenic variants, the average values \pm confidence interval $(p=5 \%)$ are presented as black bars. $\mathbf{b}$ The dependence of GUS activity level on gus gene expression. Correlation coefficients ( $r$ ) and regression coefficients $(b) \pm \mathrm{SE}$ are shown

contains conserved elements of TATA-box, CAAT-box motif and the sequence of transcription initiation site (Fig. 1). In addition, the promoter also contains some less conserved elements which may serve to fine-tune gene expression in tissues, organs or in response to different stimuli (Table 1). Among the latter ones there are probably cis-regulatory elements that ensure the activation of pro-SmAMP2 gene expression in aseptic chickweed plant after fungal infection or methyl jasmonate treatment.

Analysis of gus reporter gene expression under the control of various deletion variants of pro-SmAMP2 gene promoter in aseptic transgenic tobacco plants allowed to identify the minimum length of -455 bp retaining promoter activity. The shorter deletion variant $-290 \mathrm{bp}$ did not show any activity in heterologous plants, despite the fact that they contained a TATA-box and CAAT-box. The loss of activity may be associated with the deletion of the GT1 motif located in the area from -455 to 290 bp (Fig. 1) which is necessary for the initiation and stabilization of the transcription complex TFIIA-TBP-TATA [32]. It is unlikely that the loss of another cis-element Skn1 located in the same area of promoter sequence causes inactivation of the promoter transcriptional activity, because this regulatory element is associated with storage protein gene expression in the endosperm of a seed but not in leaves [33].

The present study was performed using the strong and constitutive viral promoter $C a M V 35 S$ as a control. With this promoter, the level of GUS activity was below $1.8 \mathrm{nmol} / \mathrm{mg} \cdot \mathrm{min}$ in individual transformants of tobacco cultivar Samsun NN (Fig. 3). In general, this activity level is comparable with the results of other studies which reported the GUS activities of $0.9-3.3 \mathrm{nmol} / \mathrm{mg} \cdot \mathrm{min}$ in individual transgenic lines of Samsun NN or Xanthi tobacco cultivars $[12,30]$. Meanwhile, there are studies which provide experimental data demonstrating GUS activity as high as $10 \mathrm{nmol} / \mathrm{mg} \cdot \mathrm{min}$ under $\mathrm{CaMV} 35 \mathrm{~S}$ promoter in some tobacco lines [25]. It is known that the level of GUS activity is highly variable in transgenic tobacco plants when using the $C a M V 35 S$ promoter which probably depends on the promoter version or measurement conditions. Anyway, GUS activity level with CaMV $35 S$ promoter demonstrated 


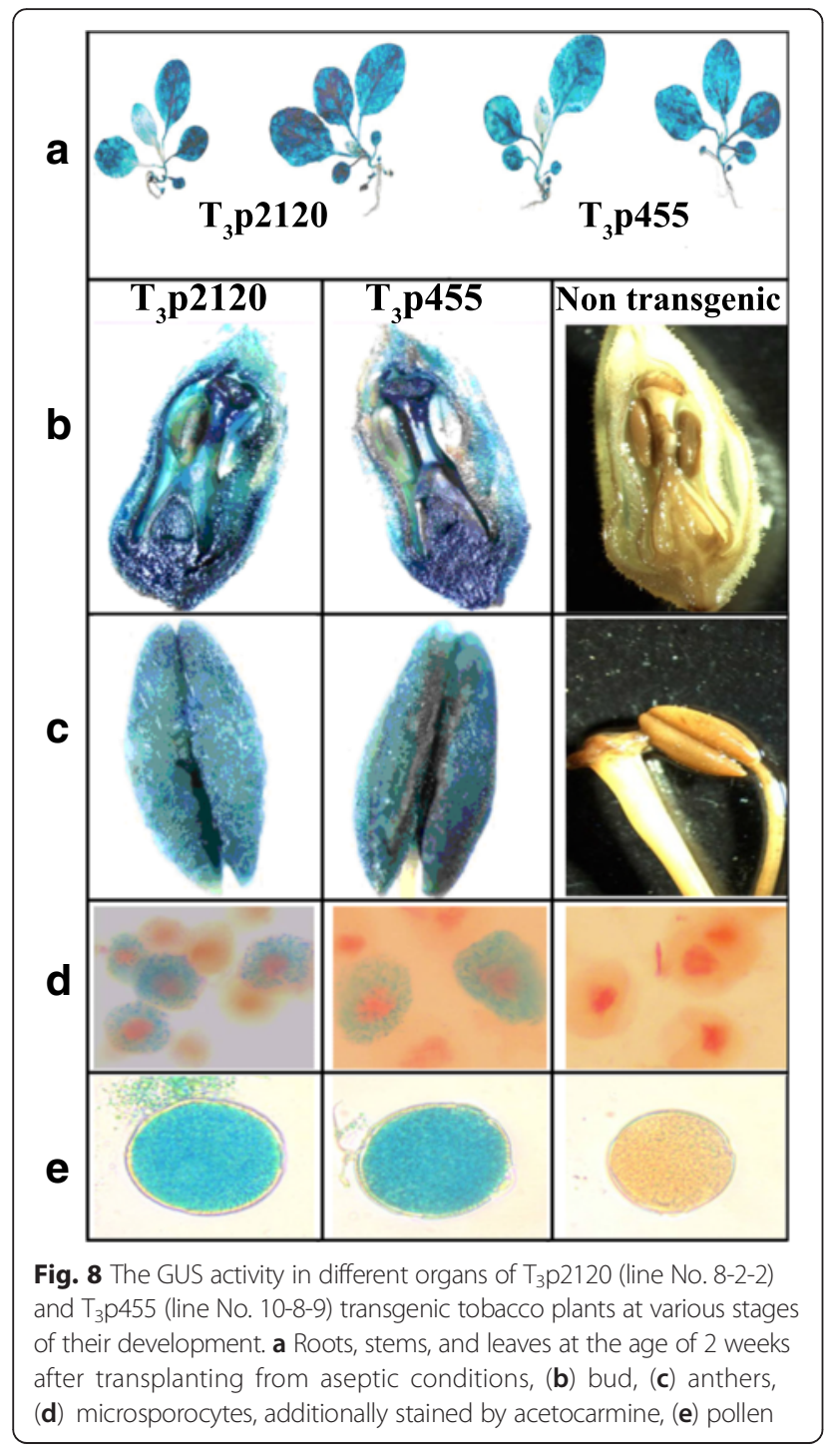

in those studies that the CaMV $35 S$ promoter can be used as a reference to compare our results with the data of other published research.

In aseptic tobacco plants, deletion variants of proSmAMP2 gene promoter region $-1504,-1149$ and $-455 \mathrm{bp}$, but not $-2120 \mathrm{bp}$, provided a significantly higher activity of the reporter protein than known viral $C a M V 35 S$ promoter (Fig. 3a). These results suggest that the pro-SmAMP2 gene promoter will be strong in dicotyledonous plants in case of stable integration into the genome. It was surprising that the longest pro-SmAMP2 promoter deletion variant $-2120 \mathrm{bp}$ was inferior to the other deletion variants and did not differ from CaMV $35 S$ promoter in efficiency. This suggests that in the segment from -2120 to 1504 bp of pro-SmAMP2 promoter region, there are regulatory elements acting negatively in aseptic tobacco plants. Likely candidates could be three TGACG motifs, which are responsible for gene expression effects of methyl jasmonate in barley Hordeum vulgare [34], and GT1 motif capable of affecting gene expression in both positive and negative way [35].

It was quite unexpected to observe an increase of GUS activity in transgenic $T_{0}$ tobacco plants after their transplantation into soil (Fig. 3), and this effect was most prominent in the $\mathrm{T}_{0} \mathrm{p} 2120$ plants, but less pronounced and comparable in magnitude in $\mathrm{T}_{0} \mathrm{p} 1504, \mathrm{~T}_{0} \mathrm{p} 1149$, and $\mathrm{T}_{0} \mathrm{p} 822$. In $\mathrm{T}_{0} \mathrm{p} 455$ plants, the increase in GUS activity was also noted, but compared to the other groups it was very small and only slightly higher than under viral promoter $C a M V$ 35S. Based on these findings, we assume that the effect of expression induction could be mainly the result of the cumulative effect of TGACG elements [34], partly W box [36] and S box [37] cis-elements involved in the response to elicitors of pathogenic fungi. Association of soil microorganisms could act as inductor of pro-SmAMP2 promoter region in transgenic tobacco plants in the conditions of greenhouse.

Previously, we have shown that the pro-SmAMP2 gene has the highest expression level in roots and flowers in chickweed plants [26]. However, in transgenic tobacco $\mathrm{T}_{\mathrm{o}} \mathrm{p} 1504, \mathrm{~T}_{\mathrm{o}} \mathrm{p} 1149, \mathrm{~T}_{\mathrm{o}} \mathrm{p} 822$, and $\mathrm{T}_{\mathrm{O}} \mathrm{p} 455$, the highest GUS activity was observed in the leaves. This may be the result of formerly described cooperative interaction of cis-elements GT1 and I box (GATA-type light regulatory element), which are present in the core part of the pro-SmAMP2 promoter, in response to light [38-41]. As tobacco plant leaves have larger surface area for light absorption than other organs, the maximum effect from GT1 and GATA motifs appeared, apparently, in them. Noteworthy, it has been demonstrated that the presence of GT element leads in some cases to the gene suppression in non-photosynthetic organs of plants [35], which correlates with our data, since GUS activity in roots of transgenic tobacco plants was significantly lower than in the above-ground parts.

The relatively high level of GUS activity was preserved in $\mathrm{T}_{1}$ transgenic tobacco plants with all deletion variants of the pro-SmAMP2 promoter region (Fig. 4a). However, the absolute values of GUS activity were significantly reduced in all groups, except $\mathrm{T}_{1} \mathrm{p} 455$, and the values were closer to the level of GUS activity in $\mathrm{T}_{0}$ aseptic plants (compare Fig. 3b and 4a). The most dramatic decrease of activity was observed in variant $\mathrm{T}_{1} \mathrm{p} 2120$, whereas the reduction was less pronounced and comparable between $\mathrm{T}_{1} \mathrm{p} 1504, \mathrm{~T}_{1} \mathrm{p} 1149$, and $\mathrm{T}_{1} \mathrm{p} 822$. The reason for the above activity changes is not clear; however, a certain similarity of this result with the above-described induction of gus expression in plants $\mathrm{T}_{0} \mathrm{p} 2120, \mathrm{~T}_{0} \mathrm{p} 1504, \mathrm{~T}_{0} \mathrm{p} 1149$, and $\mathrm{T}_{\mathrm{o}} \mathrm{p} 822$ in the soil (Fig. $3 \mathrm{~b}$ ) suggests that the reduction in GUS activity may be associated with TGACG cis-elements involved in the response to methyl jasmonate [34].

Nevertheless, the pro-SmAMP2 promoter efficiency in the progeny of transgenic $\mathrm{T}_{1}$ tobacco plants was 
comparable to the efficiency of the viral promoter CaMV S35, which can induce GUS activity in transgenic tobacco plants as high as $0.9-10.0 \mathrm{nmol} / \mathrm{mg}$. min according to published data [12, 25, 30].

High GUS activity was preserved on the level of their parent plants in transgenic tobacco plants of generations $\mathrm{T}_{2}$ and $\mathrm{T}_{3}$ transformed by pro-SmAMP2 promoter deletion variants -2120 and $-455 \mathrm{bp}$ (Fig. $4 \mathrm{~b}$ and c). Individual $\mathrm{T}_{3}$ transgenic plants did not segregate on the selective medium with hygromycin and had a comparable level of GUS activity within individual populations, which suggests their homozygosity by T-DNA loci. The average level of GUS activity in all populations of $\mathrm{T}_{3} \mathrm{p} 455$ was about $20 \mathrm{nmol} / \mathrm{mg} \cdot \min$ which was approximately two times higher than the activity in $\mathrm{T}_{3} \mathrm{p} 2120$ (Fig. $4 \mathrm{~b}$ and $\mathrm{c}$ ). These results imply the presence of cis-elements in the region from -455 to $2120 \mathrm{bp}$ of pro-SmAMP2 promoter which reduce promoter activity in tobacco plants. At the same time, it is possible that these cis-elements may contribute to the induction of the pro-SmAMP2 promoter in response to certain inducers; however, we failed to identify the inducers.

In homozygous transgenic tobacco plants $\mathrm{T}_{3} \mathrm{p} 2120$ and $\mathrm{T}_{3} \mathrm{p} 455$ grown from seed in the soil, the pro-SmAMP2 promoter led to accumulation of the GUS reporter protein during the vegetative period from day 30 to 87 (Fig. 6). In $\mathrm{T}_{3} \mathrm{p} 455$ plants, but not in $\mathrm{T}_{3} \mathrm{p} 2120$, GUS activity on day 80 reached the level detected earlier in the primary transformants grown in the soil (Fig. 3b and 6). These results confirm the assumption that negatively acting cis-elements are present in the pro-SmAMP2 promoter sequence region from 2120 to $455 \mathrm{bp}$.

More daylight hours led to increased GUS accumulation in both $\mathrm{T}_{3} \mathrm{p} 455$ and $\mathrm{T}_{3} \mathrm{p} 2120$ plants, which implies that pro-SmAMP2 promoter activity positively depends on the duration of illumination. This was expected, since its nucleotide sequence contains cis-elements able to react to changes in the duration of the light period (Fig. 1 and Table 1). It should be noted that the CaMV $35 S$ viral promoter in transgenic tobacco plants, on the contrary, had higher activity under short day condition (8/16 h) than under long day $(16 / 8 \mathrm{~h})$ [30].

Overall, we see that in successive generations, the $T_{1^{-}}$ $\mathrm{T}_{3}$ GUS activity in transgenic tobacco plants with the shortest deletion variant -455 bp of pro-SmAMP2 promoter was approximately 1.5 to 2 -fold higher than in plants with the longest deletion variant of the promoter.

Quantitative measurement of gus mRNA showed that its level is much higher than the expression of the tobacco actin gene in many lines of $\mathrm{T}_{3}$ transgenic plants. The shorter deletion variant -455 bp of pro-SmAMP2 promoter produced 2-fold higher expression level of gus mRNA than the longest deletion variant (Fig. 7a), what correlates with the GUS activity. This positive correlation between gus gene expression level and the activity of its protein product GUS (Fig. 7b) confirms that high GUS activity in transgenic tobacco plants $\mathrm{T}_{3} \mathrm{p} 2120$ and $\mathrm{T}_{3} \mathrm{p} 455$ is primarily related to the reporter gene transcription, but not to the translation of its mRNA, as was the case with $V R-A C S 1$ gene promoter from Vigna radiata L. [25]. It should be noted that all deletion variants of the proSmAMP2 promoter include its own 40 nucleotide long 5' UTR (Fig. 1). It is quite possible that it positively affects the stability of gus mRNA, but in order to make this assertion more research is needed.

The regression coefficient $b=2.37 \pm 0.30$ was obtained for GUS activity per mRNA level unit calculated for all the transgenic tobacco plants on day 58 when grown under long-day condition (Fig. 7b), that indicates the process of intensive accumulation of GUS reporter protein. This assumption is supported by the dynamics of GUS activity in transgenic plants which is also intensively increasing from day 42 to 80 (Fig. 6). The active form of the GUS protein in plants is characterized by a long half-life time [42]. Therefore, the process of high accumulation of GUS protein in transgenic plants $\mathrm{T}_{3} \mathrm{p} 2120$ and $\mathrm{T}_{3} \mathrm{p} 455$ may be explained not only by transcriptional activity of pro-SmAMP2 promoter but also by the integral effect of GUS accumulation.

In Fig. 8, it is demonstrated that the activity of the proSmAMP2 promoter deletion variants -2120 and $-455 \mathrm{bp}$, which are most different in length, is present in leaves, stems, roots, buds, anthers, microsporocytes and pollen of $\mathrm{T}_{3}$ transgenic plants. Particularly intense staining by the products of substrate X-Gluc hydrolysis was noted in the region of hypocotyl (Fig. 8a), suggesting increased activity of the pro-SmAMP2 promoter in this part of the plant. These results can be helpful when creating transgenic plants resistant to pathogens that damage crops in the region of the hypocotyl (for example, tomatoes and flax).

GUS activity in seeds of the studied plants varied greatly, probably due to inactivation of GUS enzymatic activity during storage or due to seed dehydration. It should be noted that even in plants of the same line seeds were ripening with a 1 to 3 weeks difference.

\section{Conclusion}

From the results obtained with transgenic tobacco plants, we have concluded that the pro-SmAMP2 gene promoter is strong, and its most promising deletion variant for target gene expression in plants is a variant of -455 bp length. Given the high level of gus expression in transgenic tobacco plants under control of this promoter and the high level of pro-SmAMP2 gene expression in $S$. media plants [26], it is expected that the pro-SmAMP2 gene promoter will retain high activity in other dicotyledonous plants. 


\section{Methods}

\section{Cloning nucleotide sequence of pro-SmAMP2 gene promoter region from chickweed S. media}

The seeds of $S$. media plant were collected in Central Russia. Genomic DNA extracted from leaves by GenElute Plant Genomic DNA Miniprep Kit (Sigma, USA) was used as the source of pro-SmAMP2 gene promoter region.

The nucleotide sequence of the pro-SmAMP2 gene promoter was determined using the method of "genome walking”. This was done using Genome Walker Universal Kit (Clontech Laboratories Inc., USA) and two antisense primers 1 and 2 specific for pro-SmAMP2 gene sequence (Additional file 1: Table S2).

The target nucleotide sequence was amplified by twostep PCR according to the instructions of the manufacturer. The PCR product $2400 \mathrm{bp}$ long was cloned in the vector pGEM-T (Promega, USA) and sequenced.

\section{Producing genetic constructs for Agrobacterium-mediated plant transformation}

The first nucleotide of the transcription start site (TSS) was designated as +1 . Deletion variants of the pro-SmAMP2 gene promoter region $-2120,-1504,-1149,-822,-455$ and $-290 \mathrm{bp}$ with 5'UTR (40 bp) were obtained (Fig. 1) using the reverse primer 3 and the corresponding direct primers 4-9 (Additional file 1: Table S2). For convenience of cloning, reverse primer 3 contained the sequence of the restriction site $\mathrm{NcoI}$ at its $5^{\prime}$-end, and direct primers 4-9 contained EcoRI site.

To prevent polymerase errors, PCR amplification was carried out with a mixture of $P f u$ (SibEnzyme, Russia) and Taq (Syntol, Russia) DNA polymerases in the ratio of $1: 10$ in the standard reaction buffer for thermostable polymerase $\left(60 \mathrm{mM}\right.$ Tris- $\mathrm{HCl}\left(\mathrm{pH} 8.5\right.$ at $\left.25{ }^{\circ} \mathrm{C}\right)$; $1.5 \mathrm{mM} \mathrm{MgCl} ; 25 \mathrm{mM} \mathrm{KCl} ; 10 \mathrm{mM}$ 2-mercaptoethanol; $0.1 \%$ Triton X-100) with dNTPs. The previously obtained 2400 bp fragment of the pro-SmAMP2 gene promoter region was used as DNA template. Amplification profile: denaturation $94{ }^{\circ} \mathrm{C}, 30 \mathrm{~s}$; primer annealing $60{ }^{\circ} \mathrm{C}$, $40 \mathrm{~s}$; elongation $72{ }^{\circ} \mathrm{C}, 2 \mathrm{~min} ; 25$ cycles.

Plasmid genetic constructs for plant transformation containing the reporter gene gus controlled by the deletion variants of pro-SmAMP2 gene promoter region were obtained by merging DNA fragments with the coding region of the reporter gene gusA in the plasmid pCambia1381Z (Cambia, Australia). For this purpose, PCR amplicons were purified, treated with the appropriate restriction enzymes and ligated into plasmid pCambia1381Z at the restriction sites NcoI and EcoRI. All genetic constructs obtained were verified by sequencing and designated, respectively, p2120, p1504, p1149, p822, p445 and p290. As a control, plasmid pMOG35SintGus was used in which gus reporter gene is placed under control of the viral promoter CaMV 35S [43].

\section{Agrobacterial strains for plant transformation}

Plant expression vectors p2120, p1504, p1149, p822, p445, p290 and pMOG-35SintGus were introduced into cells of Agrobacterium tumefaciens strain AGL0 by electroporation. Agrobacterial transformants containing plant expression vectors were selected on agar LB medium with the addition of antibiotics kanamycin (PhytoTechnology Laboratories, USA) and rifampicin (PhytoTechnology Laboratories, USA) at a concentration of $100 \mathrm{mg} / \mathrm{L}$ each. For plant transformation, Agrobacterium strains were grown in LB liquid medium with rifampicin $(100 \mathrm{mg} / \mathrm{L})$ and kanamycin $(100 \mathrm{mg} / \mathrm{L})$ for $20 \mathrm{~h}$ at $27^{\circ} \mathrm{C}$ and $180 \mathrm{rpm}$.

\section{Obtaining $\mathrm{T}_{0}$ generation transgenic plants}

Tobacco plants Nicotiana tabacum cultivar Samsun NN were used for Agrobacterium-mediated transformation. Regenerants were produced according to previously published methodology [26]. The antibiotic timentin (PhytoTechnology Laboratories, USA) was used at a concentration of $300 \mathrm{mg} / \mathrm{L}$ for elimination of agrobacteria. For selection of regenerants transformed by plant expression vectors p2120, p1504, p1149, p822, p445 and p290, hygromycin (PhytoTechnology Laboratories, USA) in a concentration of $50 \mathrm{mg} / \mathrm{L}$ was used; for those transformed by the plasmid pMOG-35SintGUS, kanamycin was used (100 mg/L). The regenerants were designated according to the genetic structure used for transformation. Aseptic tobacco plants were grown at $23{ }^{\circ} \mathrm{C}$, illumination $7 \mathrm{klx}$ and photoperiod $16 / 8 \mathrm{~h}$, then they were adapted to the soil within 3 days and were grown in the greenhouse at $26^{\circ} \mathrm{C}$, illumination $11 \mathrm{klx}$ and $16 / 8 \mathrm{~h}$ photoperiod, unless otherwise stated.

\section{Obtaining $T_{1}-T_{3}$ generation transgenic plants}

Seeds of $\mathrm{T}_{1}-\mathrm{T}_{3}$ were obtained by self-pollination of tobacco plants from preceding generations without obvious morphological abnormalities, demonstrating the expression of gus reporter gene and capability of seed formation. Seeds from each self-pollinated plant were collected separately, sterilized and selected on Murashige-Skoog medium [44] with hygromycin (50 mg/L) for 4 weeks. After selection was done, segregation analysis of plants into green and white phenotype was performed using Chi-square criterion. Green plants were adapted to the soil within 3 days, and were grown in the greenhouse at $26{ }^{\circ} \mathrm{C}$, illumination $11 \mathrm{klx}$ and the photoperiod 16/8 h.

To obtain homozygous plants of $T_{2}$ generation, the $T_{1}$ plants from populations with monogenic inheritance of transgenes were used to avoid the influence of the number of independent T-DNA insertions on GUS activity level. Plants with activity level approximately two times higher than in other plants of the same population were selected as the parent $\mathrm{T}_{1}$ plants, which suggested their homozygosity by T-DNA loci. The homozygous $\mathrm{T}_{3}$ plants were obtained on the same way. 


\section{Quantitation of the reporter protein beta-glucuronidase (GUS) activity}

GUS activity was measured in extracts of tobacco plants according to the method by Jefferson et al. [45]. Three tissue samples were analyzed from each individual transgenic plant. To obtain protein extracts, plant tissue samples (about 10-20 mg) were homogenized in $150 \mu \mathrm{L}$ of extraction buffer (50 mM NaH $\mathrm{PO}_{4}(\mathrm{pH} 7.0) ; 10$ mM EDTA; $0.1 \%$ Triton X-100; $0.1 \%(\mathrm{w} / \mathrm{v})$ sodium laurylsarcosine; $10 \mathrm{mM}$ beta-mercaptoethanol), centrifuged $10 \mathrm{~min}$ at $15.000 \mathrm{rpm}, 4{ }^{\circ} \mathrm{C}$. Next, $100 \mu \mathrm{L}$ of supernatant was collected and re-centrifuged under the same conditions, and $70 \mu \mathrm{L}$ of the supernatant was taken for analysis. The samples obtained were stored frozen at minus $70{ }^{\circ} \mathrm{C}$.

GUS activity was measured for $30 \mathrm{~min}$ at $37^{\circ} \mathrm{C}$ in $100 \mu \mathrm{L}$ of extraction buffer with 4-methylumbelliferyl-Dglucuronide (4MUG) (PhytoTechnology Laboratories, USA) at a final concentration of $1 \mathrm{mM}$. The reaction was stopped by adding $900 \mu \mathrm{L}$ of $0.2 \mathrm{M} \mathrm{Na}_{2} \mathrm{CO}_{3}$. Fluorescence was excited at $365 \mathrm{~nm}$ and measured at $455 \mathrm{~nm}$ (Perkin Elmer LS55, USA). Calibration of fluorescence was performed using a solution of 4-methylumbelliferone (4MU) (Sigma-Aldrich, USA) in $0.2 \mathrm{M} \mathrm{Na}_{2} \mathrm{CO}_{3}$. GUS activity was calculated after determining the concentration of protein in extracts by Bradford [46] using a solution of bovine serum albumin as standard. The results of GUS activity measurement from each individual transgenic plant are presented as average value from three tissue samples $\pm \mathrm{SE}$.

Each aseptic tobacco $\mathrm{T}_{0}$ regenerant was analyzed in 1.5 months after rooting the plant on the medium with a selective agent, immediately before planting in soil. Each $\mathrm{T}_{0}-\mathrm{T}_{3}$ transgenic tobacco plant was analyzed 6 weeks after transplanting from aseptic conditions into the soil. Mature leaves (about $20 \mathrm{~cm}$ ) from medium level were used for the analysis. One 10-12 mg cutting was taken to measure GUS activity in the leaves. Fragments of sprout stems $(8-10 \mathrm{~cm})$ with a diameter of about $1 \mathrm{~cm}$ (15-20 mg) were used for GUS activity analysis in the stems of tobacco plants. GUS activity was analyzed in the flowers of tobacco plants during abundant flowering, entire flower was used for the analysis. Adventitious roots about $1 \mathrm{~cm}$ long (weight $15-20 \mathrm{mg}$ ) from 8 to $10 \mathrm{~cm}$ sprouts were used for GUS activity measurement in the roots of tobacco plants.

GUS activity level at different daylight duration was studied in the period from day 30 after $\mathrm{T}_{3}$ homozygous seeds germination until the first fruits ripening on day 87. The plants were grown directly from seed in the soil, bypassing selection stage on the selective medium with hygromycin, which had duration of 28 days in other experiments. Seven transgenic tobacco plants from each line were analyzed, three of them were grown under short-day (12/12 h) and the other four under long-day (16/8 h) condition.
Histochemical staining of $\mathrm{T}_{3}$ plants using $\mathrm{X}$-Gluc

Five plants from each population were studied: populations No. 8-2-2 and 19-1-2 for $\mathrm{T}_{3} \mathrm{p} 2120$ transgene; populations No. 10-8-9 and 14-3-3 for $\mathrm{T}_{3} \mathrm{p} 455$ transgene (Fig. 5a). Expression of the gus reporter gene in different organs (root, stem, leaf, bud, anthers) and at different stages of plant development (gametophytic and sporophytic) was studied using histochemical staining of tissues with GUS substrate X-Gluc.

Whole transgenic tobacco plants grown in soil for 2 weeks after transplanting from aseptic condition, or buds, anthers, microsporocytes and pollen during flowering and fruiting were used for staining. For detection of GUS activity staining was performed according to the method by Jefferson et al. [42]. Whole plants or their organs were fully immersed in the staining solution (10 mM EDTA; $0.1 \%$ Triton X-100; $1 \mathrm{mM} \mathrm{K}{ }_{3} \mathrm{Fe}(\mathrm{CN})_{6}$; $1 \mathrm{mM} \mathrm{K}{ }_{4} \mathrm{Fe}(\mathrm{CN})_{6}$; 5-bromo-4-chloro-3-indolyl- $\beta$-D-glucuronic acid, sodium salt (X-Gluc) (PhytoTechnology Laboratories, USA) $2 \mathrm{mM}$ in $0.1 \mathrm{M}$ phosphate buffer, $\mathrm{pH}$ 7.0). Samples were exposed to vacuum (80 kPa) for $30 \mathrm{~min}$, then incubated at $37^{\circ} \mathrm{C}$ for $24 \mathrm{~h}$ and washed in $70 \%$ ethanol.

\section{RNA extraction and synthesis of first chain cDNA}

Total RNA was extracted from plant leaves (100 mg) using Trizol reagent (Invitrogen, USA) according to the instructions of the manufacturer. To eliminate genomic DNA contamination, RNA was treated with DNase RQ1 RNase-Free (Promega, USA) and stored at minus $70{ }^{\circ} \mathrm{C}$.

The first chain cDNA was obtained by reverse transcription using the oligonucleotide oligo-dT (Syntol, Russia) as a primer and RNA-dependent DNA polymerase of Malone mice leukemia virus (M-MLV). The final incubation mixture contained $50 \mathrm{mM}$ Tris- $\mathrm{HCl}(\mathrm{pH} 8.2), 8 \mathrm{mM} \mathrm{MgSO}_{4}$, $10 \mathrm{mM}$ DTT, $50 \mathrm{mM} \mathrm{KCl,} 0.4 \mathrm{mM}$ each of dNTPs, 100 pmol oligo-dT primer, 5 units of RNase inhibitor, 25 units of reverse transcriptase and $1 \mu \mathrm{g}$ of total RNA. The reaction was carried out for $1 \mathrm{~h}$ at $37^{\circ} \mathrm{C}$.

\section{Real-time RT-PCR}

Four transgenic plants of each population from each deletion variant $T_{3} p 2120$ (No. 8-2-2 and No. 19-1-2) and $\mathrm{T}_{3} \mathrm{p} 455$ (No. 14-3-3 and No. 10-8-9) at the age of 58 days from the moment of seed germination in the soil grown under long-day condition $(16 / 8 \mathrm{~h})$ were used to study correlation between GUS activity and gus gene mRNA content.

Evaluation of gus gene expression relative to the expression of actin gene was performed as triplicate using specific primers (Additional file 1: Table S3, except gus-1 and gus-2 primers). The primers were selected so that the length of the PCR product was less than 150 base pairs. Specificity of amplification was checked by electrophoresis 
in $1.5 \%$ agarose gel; if single amplicon was observed, amplification was assumed to be specific. Additionally, to confirm the specificity of the primers used, amplification products were cloned in the vector pGEM-T and sequenced on an automated sequencing machine AhFexpress II (Amersham Pharmacia Biotech, USA). Real-time PCR was performed on a cycler CFX96 (BioRad, USA) in the presence of the intercalating dye SYBR Green I in $25 \mu \mathrm{L}$ of reaction mixture containing $50 \mathrm{mM} \mathrm{KCl}, 10 \mathrm{mM}$ Tris- $\mathrm{HCl}$ (pH 8.3), $1.5 \mathrm{mM} \mathrm{MgCl}_{2}, 5 \mathrm{mM}$ each of dNTPs, 1 unit of Taq DNA polymerase, $5 \mu \mathrm{M}$ specific primers, and $0.01 \mu \mathrm{L}$ of the reverse transcription product.

Real-time PCR was performed under the following cycling conditions: 1 cycle $94{ }^{\circ} \mathrm{C}, 3 \mathrm{~min} ; 40$ cycles of $\left(94{ }^{\circ} \mathrm{C}, 15 \mathrm{~s} ; 60{ }^{\circ} \mathrm{C}, 15 \mathrm{~s} ; 72{ }^{\circ} \mathrm{C}, 30 \mathrm{~s}\right)$. Specificity of amplification was checked after the last PCR cycle by analysis of the melting curve (from 55 to $95{ }^{\circ} \mathrm{C}$ ). Reaction efficiency was determined by performing real-time PCR analysis with several dilution steps of cDNA. Statistical processing of PCR data was performed using the program qgene-96 [47]. For expression analysis, $\Delta \Delta \mathrm{C}_{\mathrm{t}}$ method was applied [48].

To calculate the changes of gene expression in the test samples compared to control ones, the following equation was used: $C=(1+E)^{-}{ }^{-\Delta A t}$, where $\Delta \Delta C_{t}=\Delta C_{t}$ (gus) $-\Delta C_{t}$ (actin), $C_{t}$ (gus) - threshold cycle difference between test and control samples for gus gene, $\Delta \mathrm{C}_{\mathrm{t}}$ (actin) - threshold cycle difference between test and control samples for actin gene, $\mathrm{E}$ - reaction efficiency.

\section{Southern blot hybridization}

Tobacco genomic DNA $(20 \mu \mathrm{g})$ was digested overnight at $37{ }^{\circ} \mathrm{C}$ with $60 \mathrm{U}$ EcoRI which cut the T-DNA of p2120 and p455 at a single position (see Producing genetic constructs for Agrobacterium-mediated plant transformation). The fragments were separated on a $0.9 \%$ agarose gel and transferred to a positive-charged nylon membrane Hybond $\mathrm{N}+$ (GE Healthcare,UK) by capillary blotting following the manufacturer's instructions. The DNA probe was constructed by PCR using plasmid p2120 as the template, and primers gus- 1 and gus-2 (Additional file 1: Table S3). Probe DNA (740 bp) was labeled with alkaline phosphatase using Amersham Gene Image AlkPhos Direct Labelling and Detection System (GE Healthcare, UK). Prehybridization, hybridization (overnight at $60{ }^{\circ} \mathrm{C}$ ) with alkaline phosphatase-labeled probe, and subsequent washings of the membrane were carried out according to the AlkPhos Direct Labeling System protocol. Detection was performed using CDP-Star detection reagent following the manufacturer's directions (Amersham CDP-Star Detection reagent, GE Healthcare, UK).

\section{Ethics approval and consent to participate}

Not applicable.

\section{Consent for publication}

Not applicable.

\section{Availability of data and material}

The dataset supporting the conclusions of this article is available in the GenBank repository (accession number KX196447).

\section{Additional files}

Additional file 1: Table S1. The GUS activity in Top290 and wild type tobacco plants. Table S2. Primers for cloning pro-SmAMP2 gene promoter region and its deletion variants. Table $\mathbf{S 3}$. Primers used in the gene expression measurements and Southern blot hybridization. (DOC 67 kb)

Additional file 2: Figure S1. Relative GUS activity in different organs of $\mathrm{T}_{0}$ transgenic tobacco plants. The activity of GUS in leaves was taken as $100 \%$. (TIF $418 \mathrm{~kb}$ )

\section{Abbreviations}

4MU: 4-methylumbelliferone; 4MUG: 4-methylumbelliferyl $\beta$-D-galactopyranoside; ARE: adenylate-uridylate-rich element; bp: base pair(s); CaMV: cauliflower mosaic virus; dNTP: deoxynucleoside triphosphates; EDTA: ethylenediaminetetraacetic acid; GCN4: general control nonderepressible; GUS: $\beta$-glucuronidase; klx: kilolux; LB medium: Luria broth medium; LRE: light responsive element; mRNA: messenger ribonucleic acid; MYB: myeloblastosis; PCR: polymerase chain reaction; PR-protein: pathogenesis-related; SE: standard error; SmAMP: Stellaria media antimicrobial peptide; T-DNA: transfer deoxyribonucleic acid; UTR: untranslated region; X-Gluc: 5-bromo-4-chloro-3-indolyl- $\beta$-D-glucuronide.

\section{Competing interests}

The authors declare that they have no competing interests.

\section{Authors' contributions}

RK drafted the main body of the manuscript, participated in the design of the study and carried out the segregation calculations; DV drafted the part of the manuscript, participated in the design of the study and carried out the mRNA extraction and qPCR analysis; RS and W cloned, sequenced the promoter and prepared the genetic constructs; VK and EV performed the transformation, selection and growing of the transgenic plants; SS carried out the GUS activity analysis; AB participated in the design of the study, drafted the part of the manuscript and participated in the discussion. All authors read and approved the final manuscript

\section{Acknowledgements}

The present study was supported the Ministry of education and science of the Russian Federation, agreement No (RFMEFI60414X0028). The work was performed with the use of scientific equipment of Center for collective use "Biotechnology" at All-Russia Research Institute of Agricultural Biotechnology (Moscow, Russia).

\section{Author details}

${ }^{1}$ All-Russia Research Institute of Agricultural Biotechnology, Timiriazevskaya 42, 127550 Moscow, Russia. ${ }^{2}$ IBC Generium LLC, Vladimirskaya 14, 601125 Volginsky, Russia.

Received: 16 November 2015 Accepted: 11 May 2016

Published online: 18 May 2016

\section{References}

1. Potenza C, Aleman L, Sengupta-Gopalan C. Targeting transgene expression in research, agricultural, and environmental applications: Promoters used in plant transformation. In Vitro Cell Dev Biol-Plant. 2004;40(1):1-22.

2. Zhu C, Naqvi S, Gomez-Galera S, Pelacho AM, Capell T, Christou P. Transgenic strategies for the nutritional enhancement of plants. Trends Plant Sci. 2007;12(12):548-55.

3. Naqvi S, Farre G, Sanahuja G, Capell T, Zhu C, Christou P. When more is better: multigene engineering in plants. Trends Plant Sci. 2010;15(1):48-56. 
4. Mette MF, van der Winden J, Matzke MA, Matzke AJ. Production of aberrant promoter transcripts contributes to methylation and silencing of unlinked homologous promoters in trans. EMBO J. 1999;18(1):241-8.

5. Lessard PA, Kulaveerasingam H, York GM, Strong A, Sinskey AJ. Manipulating gene expression for the metabolic engineering of plants. Metab Eng. 2002;4(1):67-79.

6. Mourrain $\mathrm{P}$, van Blokland $\mathrm{R}$, Kooter JM, Vaucheret $\mathrm{H}$. A single transgene locus triggers both transcriptional and post-transcriptional silencing through doublestranded RNA production. Planta. 2007;225(2):365-79.

7. Odell JT, Nagy F, Chua NH. Identification of DNA sequences required for activity of the cauliflower mosaic virus 35 S promoter. Nature. 1985;313(6005):810-2.

8. Porto MS, Pinheiro MP, Batista VG, dos Santos RC, Filho Pde A, de Lima LM. Plant promoters: an approach of structure and function. Mol Biotechnol. 2014;56(1):38-49.

9. Al-Kaff NS, Kreike MM, Covey SN, Pitcher R, Page AM, Dale PJ. Plants rendered herbicide-susceptible by cauliflower mosaic virus-elicited suppression of a $35 \mathrm{~S}$ promoter-regulated transgene. Nat Biotechnol. 2000;18(9):995-9.

10. Stam M, Mol JNM, Kooter JM. Review Article: The silence of genes in transgenic plants. Ann Bot. 1997;79(1):3-12.

11. Jakowitsch J, Papp I, Moscone EA, van der Winden J, Matzke M, Matzke AJ. Molecular and cytogenetic characterization of a transgene locus that induces silencing and methylation of homologous promoters in trans. Plant J. 1999;17(2):131-40.

12. Kumar D, Patro S, Ranjan R, Sahoo DK, Maiti IB, Dey N. Development of useful recombinant promoter and its expression analysis in different plant cells using confocal laser scanning microscopy. PLoS One. 2011;6(9):e24627.

13. Patro S, Kumar D, Ranjan R, Maiti IB, Dey N. The development of efficient plant promoters for transgene expression employing plant virus promoters. Mol Plant. 2012;5(4):941-4.

14. McElroy D, Zhang W, Cao J, Wu R. Isolation of an efficient actin promoter for use in rice transformation. Plant Cell. 1990;2(2):163-71.

15. Christensen AH, Sharrock RA, Quail PH. Maize polyubiquitin genes: structure, thermal perturbation of expression and transcript splicing, and promoter activity following transfer to protoplasts by electroporation. Plant Mol Biol. 1992;18(4):675-89.

16. Cornejo MJ, Luth D, Blankenship KM, Anderson OD, Blechl AE. Activity of a maize ubiquitin promoter in transgenic rice. Plant Mol Biol. 1993;23(3):567-81.

17. Park SH, Yi N, Kim YS, Jeong MH, Bang SW, Choi YD, et al. Analysis of five novel putative constitutive gene promoters in transgenic rice plants. J Exp Bot. 2010;61(9):2459-67.

18. Wang J, Oard JH. Rice ubiquitin promoters: deletion analysis and potential usefulness in plant transformation systems. Plant Cell Rep. 2003;22(2):129-34.

19. Coussens G, Aesaert S, Verelst W, Demeulenaere M, De Buck S, Njuguna E, et al. Brachypodium distachyon promoters as efficient building blocks for transgenic research in maize. J Exp Bot. 2012;63(11):4263-73.

20. Callis J, Raasch JA, Vierstra RD. Ubiquitin extension proteins of Arabidopsis thaliana. Structure, localization, and expression of their promoters in transgenic tobacco. J Biol Chem. 1990;265(21):12486-93.

21. Zhang N, McHale LK, Finer JJ. Isolation and characterization of "GmScream" promoters that regulate highly expressing soybean (Glycine max Merr.) genes. Plant Sci. 2015;241:189-98.

22. De La Torre CM, Finer JJ. The intron and $5^{\prime}$ distal region of the soybean Gmubi promoter contribute to very high levels of gene expression in transiently and stably transformed tissues. Plant Cell Rep. 2015;34(1):111-20.

23. Baszczynski C, Barbour E, Miki B, ALS3 promoter. US: Pioneer Hi-Bred International; 1997. US5659026 A.

24. Xiao K, Zhang C, Harrison M, Wang Z-Y. Isolation and characterization of a novel plant promoter that directs strong constitutive expression of transgenes in plants. Mol Breeding. 2005;15(2):221-31.

25. Cazzonelli Cl, McCallum EJ, Lee R, Botella JR. Characterization of a strong, constitutive mung bean (Vigna radiata L.) promoter with a complex mode of regulation in planta. Transgenic Res. 2005;14(6):941-67.

26. Shukurov RR, Voblikova VD, Nikonorova AK, Komakhin RR, Komakhina W, Egorov TA, et al. Transformation of tobacco and Arabidopsis plants with Stellaria media genes encoding novel hevein-like peptides increases their resistance to fungal pathogens. Transgenic Res. 2012;21(2):313-25.

27. Higo K, Ugawa Y, Iwamoto M, Korenaga T. Plant cis-acting regulatory DNA elements (PLACE) database: 1999. Nucleic Acids Res. 1999;27(1):297-300.

28. Prestridge DS. SIGNAL SCAN: a computer program that scans DNA sequences for eukaryotic transcriptional elements. Comput Appl Biosci. $1991 ; 7(2): 203-6$
29. Lescot M, Dehais P, Thijs G, Marchal K, Moreau Y, Van de Peer Y, et al. PlantCARE, a database of plant cis-acting regulatory elements and a portal to tools for in silico analysis of promoter sequences. Nucleic Acids Res. 2002:30(1):325-7.

30. Schnurr JA, Guerra DJ. The CaMV 355 promoter is sensitive to shortened photoperiod in transgenic tobacco. Plant Cell Rep. 2000;19(3):279-82.

31. Sawant S, Singh P, Gupta S, Madnala R, Tuli R. Conserved nucleotide sequences in highly expressed genes in plants. J Genet. 1999;78(2):123-31.

32. Le Gourrierec J, Li YF, Zhou DX. Transcriptional activation by Arabidopsis GT-1 may be through interaction with TFIIA-TBP-TATA complex. Plant J. 1999:18(6):663-8.

33. Washida H, Wu CY, Suzuki A, Yamanouchi U, Akihama T, Harada K, et al. Identification of cis-regulatory elements required for endosperm expression of the rice storage protein glutelin gene GluB-1. Plant Mol Biol. 1999;40(1):1-12.

34. Rouster J, Leah R, Mundy J, Cameron-Mills V. Identification of a methyl jasmonate-responsive region in the promoter of a lipoxygenase 1 gene expressed in barley grain. Plant J. 1997;11(3):513-23.

35. Zhou DX. Regulatory mechanism of plant gene transcription by GT-elements and GT-factors. Trends Plant Sci. 1999;4(6):210-4.

36. Rushton PJ, Torres JT, Parniske M, Wernert P, Hahlbrock K, Somssich IE. Interaction of elicitor-induced DNA-binding proteins with elicitor response elements in the promoters of parsley PR1 genes. EMBO J. 1996;15(20):5690-700.

37. Kirsch C, Takamiya-Wik M, Schmelzer E, Hahlbrock K, Somssich IE. A novel regulatory element involved in rapid activation of parsley ELI7 gene family members by fungal elicitor or pathogen infection. Mol Plant Pathol. 2000; 1(4):243-51.

38. Puente P, Wei N, Deng XW. Combinatorial interplay of promoter elements constitutes the minimal determinants for light and developmental control of gene expression in Arabidopsis. EMBO J. 1996;15(14):3732-43.

39. Chattopadhyay S, Puente P, Deng XW, Wei N. Combinatorial interaction of light-responsive elements plays a critical role in determining the response characteristics of light-regulated promoters in Arabidopsis. Plant J. 1998; 15(1):69-77.

40. Terzaghi WB, Cashmore AR. Photomorphogenesis. Seeing the light in plant development. Curr Biol. 1995:5(5):466-8.

41. Escobar MA, Franklin KA, Svensson AS, Salter MG, Whitelam GC, Rasmusson AG. Light regulation of the Arabidopsis respiratory chain. Multiple discrete photoreceptor responses contribute to induction of type II NAD(P)H dehydrogenase genes. Plant Physiol. 2004;136(1):2710-21.

42. Quaedvlieg NM, Schlaman HM, Admiraal P, Wijting S, Stougaard J, Spaink H. Fusions between green fluorescent protein and $\beta$-glucuronidase as sensitive and vital bifunctional reporters in plants. Plant Mol Biol. 1998;38(5):861-73.

43. Strelnikova SR, Voblikova VD, Shukurov RR, Babakov AV, Komakhin RA. Study of novel plant promoter of gene proSmAMP2 from Stellaria media by Agrobacterium infiltration of plants. Biotechnol Russ. 2014;3:8-17.

44. Murashige T, Skoog F. A Revised Medium for rapid growth and bio assays with tobacco tissue cultures. Physiol Plant. 1962;15(3):473-97.

45. Jefferson RA, Burgess SM, Hirsh D. beta-glucuronidase from Escherichia coli as a gene-fusion marker. Proc Natl Acad Sci U S A. 1986;83(22):8447-51.

46. Bradford MM. A rapid and sensitive method for the quantitation of microgram quantities of protein utilizing the principle of protein-dye binding. Anal Biochem. 1976;72:248-54.

47. Muller PY, Janovjak H, Miserez AR, Dobbie Z. Processing of gene expression data generated by quantitative real-time RT-PCR. Biotechniques. 2002;32(6): 1372. $-4,6,8-9$.

48. Bustin SA. Absolute quantification of mRNA using real-time reverse transcription polymerase chain reaction assays. J Mol Endocrinol. 2000;25(2):169-93. 